NATIONAL LABORATORY

\title{
Reactivity Accountability Attributed to Beryllium Reflector Poisons in the High Flux Isotope Reactor
}

\section{December 2009}

\author{
D. Chandler \\ R. T. Primm, III \\ G. I. Maldonado
}
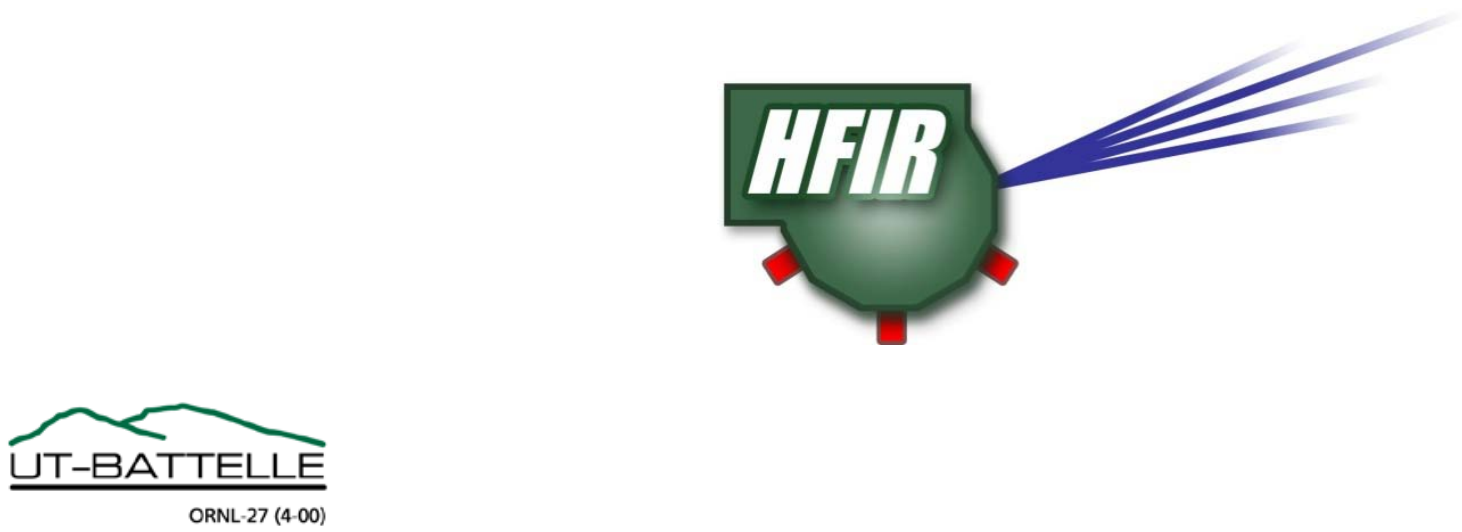


\section{DOCUMENT AVAILABILITY}

Reports produced after January 1, 1996, are generally available free via the U.S. Department of Energy (DOE) Information Bridge.

Web site http://www.osti.gov/bridge

Reports produced before January 1, 1996, may be purchased by members of the public from the following source.

National Technical Information Service

5285 Port Royal Road

Springfield, VA 22161

Telephone 703-605-6000 (1-800-553-6847)

TDD 703-487-4639

Fax 703-605-6900

E-mail info@ntis.gov

Web site http://www.ntis.gov/support/ordernowabout.htm

Reports are available to DOE employees, DOE contractors, Energy Technology Data Exchange (ETDE) representatives, and International Nuclear Information System (INIS) representatives from the following source.

Office of Scientific and Technical Information

P.O. Box 62

Oak Ridge, TN 37831

Telephone 865-576-8401

Fax 865-576-5728

E-mail reports@osti.gov

Web site http://www.osti.gov/contact.html

This report was prepared as an account of work sponsored by an agency of the United States Government. Neither the United States Government nor any agency thereof, nor any of their employees, makes any warranty, express or implied, or assumes any legal liability or responsibility for the accuracy, completeness, or usefulness of any information, apparatus, product, or process disclosed, or represents that its use would not infringe privately owned rights. Reference herein to any specific commercial product, process, or service by trade name, trademark, manufacturer, or otherwise, does not necessarily constitute or imply its endorsement, recommendation, or favoring by the United States Government or any agency thereof. The views and opinions of authors expressed herein do not necessarily state or reflect those of the United States Government or any agency thereof. 
Research Reactors Division

\section{REACTIVITY ACCOUNTABILITY ATTRIBUTED TO BERYLLIUM REFLECTOR POISONS IN THE HIGH FLUX ISOTOPE REACTOR}

D. Chandler

R. T. Primm, III

G. I. Maldonado

December 2009

Prepared by

OAK RIDGE NATIONAL LABORATORY

Oak Ridge, Tennessee 37831-6283

managed by

UT-BATTELLE, LLC

for the

U.S. DEPARTMENT OF ENERGY

under contract DE-AC05-O0OR22725 



\section{CONTENTS}

Page

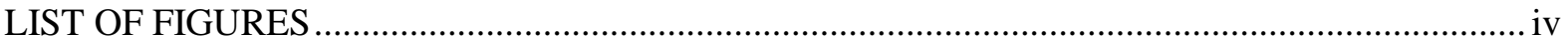

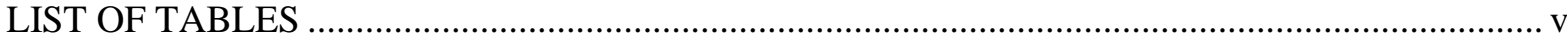

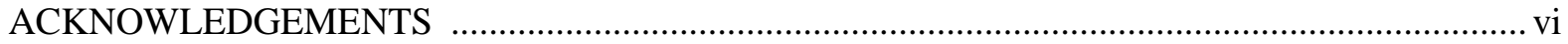

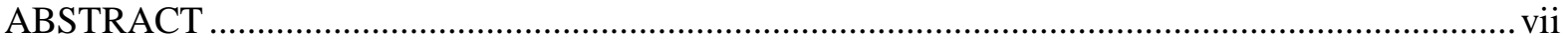

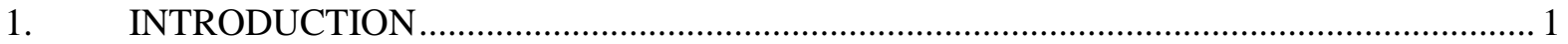

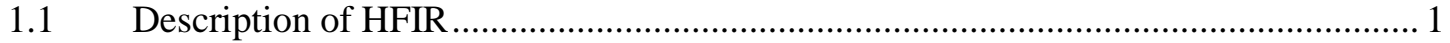

$1.2 \quad$ Effects of Irradiation on Beryllium .................................................................... 2

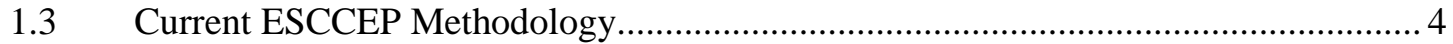

$1.4 \quad$ HFIR Cycle 408 - Restart Following a Long Outage .................................................. 4

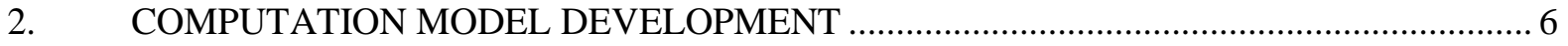

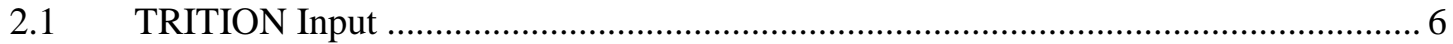

2.1.1 Cross Section Processing Part of TRITON ...................................................... 6

2.1.2 Conversion of MCNP HFIR Model to a KENO V.a Model .......................... 7

2.1.2.1 Flux Trap Target Region (FTT) ............................................. 8

2.1.2.2 Fuel Elements (FEs) ......................................................... 9

2.1.2.3 Control Elements (CEs).............................................................. 11

2.1.2.4 Beryllium Reflector ................................................................. 11

2.1.3 Depletion/Decay Portion of TRITON Input................................................... 15

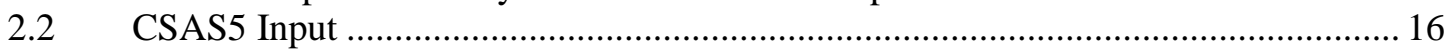

3. BERYLLIUM IRRADIATION POISONING AND REACTIVITY CALCULATIONS ....... 18

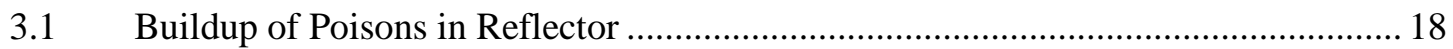

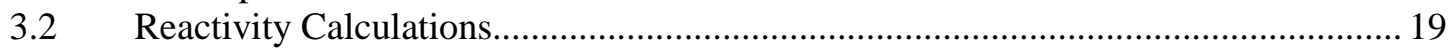

3.3 Proposed Shutdown Poison Accountability Procedure .............................................. 21

3.4 Validation of Proposed Methodology Against ASCCEP Data .................................. 22

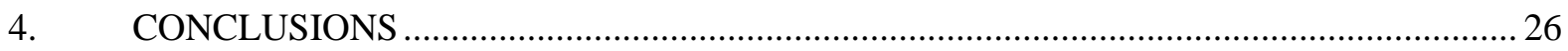

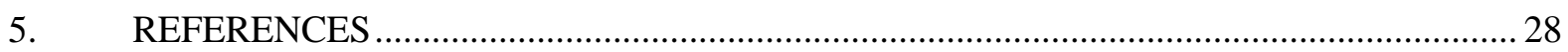

APPENDIX A Benchmarking of SCALE Model ....................................................................... A-1

APPENDIX B Best Fit Equations and Comparisons..................................................................... B-1 


\section{LIST OF FIGURES}

1. Cross section of HFIR at the horizontal midplane ......................................................

2. Beryllium and reflector poison cross section data ........................................................

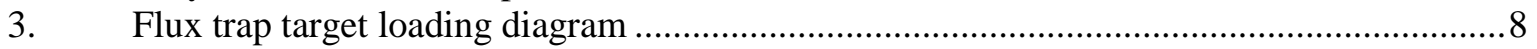

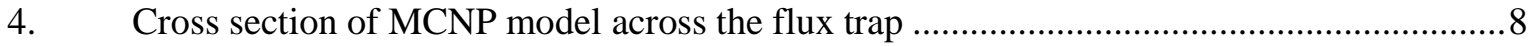

5. Cross section of SCALE model across the flux trap ........................................................

6. Cross section of MCNP model across the flux trap and fuel elements .............................10

7. Cross section of SCALE model across the flux trap and fuel elements .............................10

8. Modeled ${ }^{235} \mathrm{U}$ atomic concentration distribution ......................................................... 10

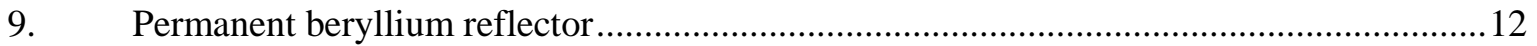

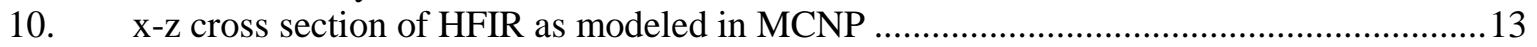

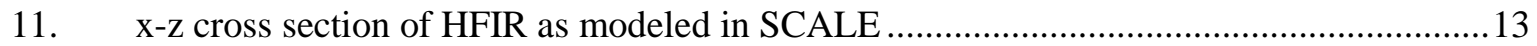

12. Cross section of HFIR MCNP model at the horizontal midplane .....................................14

13. Cross section of HFIR SCALE model at the horizontal midplane..................................14

14. Isometric view of HFIR SCALE model .................................................................... 15

14. $\quad{ }^{6} \mathrm{Li},{ }^{3} \mathrm{H}$, and ${ }^{3} \mathrm{He}$ atomic concentration in reflector as a function of simulation time...........18

15. ${ }^{3}$ He reactivity effects as a function of shutdown time with respect to reference case.........20

16. Comparison of current RRD procedure and newly derived ${ }^{3} \mathrm{He}$ poison estimates..............21

17. Comparison of current and proposed ESCCEP methodologies against ASCCEP data ......23

18. Box plot for current and proposed methodologies ........................................................24

A1. Cycle 400 simulated control element withdrawal curve and discretization of steps used

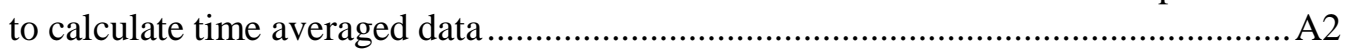

A2. Comparison of time averaged fluxes calculated in MCNP and fluxes used in SCALE.....A3

B1. Comparison of $1^{\text {st }}, 2^{\text {nd }}$, and $3^{\text {rd }}$ order best fit equations to ASCCEP data......................... B2 


\section{LIST OF TABLES}

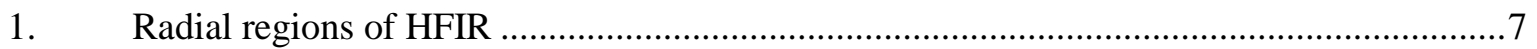

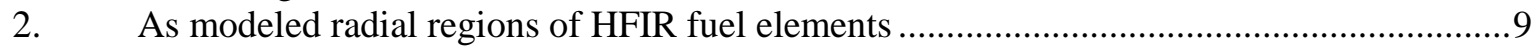

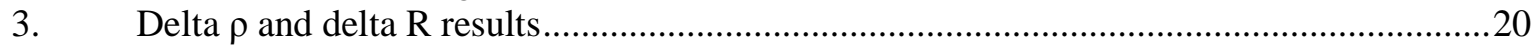

4. Statistical results for current and proposed methodologies ..............................................24

A1. Multiplication factor comparison for MCNP and SCALE models ..................................A1

B1. Differential worth of control elements at ESCCEP ......................................................... B1

B2. Comparison of $1^{\text {st }}, 2^{\text {nd }}$, and $3^{\text {rd }}$ order best fit equations to calculated results..................... B2 


\section{ACKNOWLEDGMENTS}

The authors would like to acknowledge the support given by Germina Ilas and Mark DeHart, Nuclear Science and Technology Division, Oak Ridge National Laboratory, who assisted with the computational methods. The authors would also like to thank the technical reviewers, Germina Ilas of the Nuclear Science and Technology Division and Kevin Smith of the Research Reactors Division, Oak Ridge National Laboratory, for their efforts and comments. The authors would also like to acknowledge and thank Mary Wells for her efforts in preparing and editing this report. 


\begin{abstract}
The objective of this study is to develop a methodology to predict the reactivity effect of ${ }^{3} \mathrm{He},{ }^{6} \mathrm{Li}$, and other poisons in the High Flux Isotope Reactor's (HFIR) beryllium reflector as a function of outage time between cycles. The reactivity worth at startup of the HFIR after the reactor has been shut-down for long periods of time has been incorrectly predicted in the past. The incorrect prediction was assumed to be due to the erroneous calculation of ${ }^{3} \mathrm{He}$ buildup in the beryllium reflector. It is necessary to develop a better estimate of the start-of-cycle symmetric critical control element positions since if the estimated and actual symmetrical critical control element positions differ by more than $\$ 1.55$ in reactivity (approximately one-half inch in control element startup position), HFIR is to be shutdown and a technical evaluation performed to resolve the discrepancy prior to restart.

${ }^{3} \mathrm{He}$ is generated and depleted during operation, but during an outage, the depletion of ${ }^{3} \mathrm{He}$ ceases because it is a stable isotope. ${ }^{3} \mathrm{He}$ is born from the radioactive decay of tritium, and thus the concentration of ${ }^{3} \mathrm{He}$ increases during shutdown. The SCALE code system, specifically the TRITON and CSAS5 sequences in SCALE were utilized in this study to deplete the beryllium reflector and calculate effective eigenvalues. An equation relating the down time $\left(\mathrm{t}_{\mathrm{d}}\right)$ to the change in symmetric control element position was established and validated against measurements for approximately 40 HFIR operating cycles. The newly-derived correlation was shown to improve accuracy of reactivity predictions for startup after long periods of down time.
\end{abstract}


This page blank. 


\section{INTRODUCTION}

\subsection{DESCRIPTION OF HFIR}

The High Flux Isotope Reactor (HFIR) is a versatile flux-trap type research reactor that was designed to produce gram quantities of transuranium isotopes such as californium-252. HFIR has also been used for other applications: thermal-neutron and cold-neutron scattering, materials irradiation, and neutron activation analysis. Currently, HFIR operates at a power level of $85 \mathrm{MW}$ for 23 to 27 day cycles and has a peak thermal neutron flux of $2.6 \times 10^{15} \mathrm{n} / \mathrm{cm}^{2} / \mathrm{s}$.

A bundle consisting of 37 target positions is located in the central region of HFIR and is referred to as the flux-trap. On the outside of the flux-trap are the fuel elements, two concentric rings referred to as the inner and outer fuel elements. The inner fuel element (IFE) and the outer fuel element (OFE) contain 171 and 369 fuel plates, respectively. The fuel plates, which are involute in shape, are made of highly enriched uranium (HEU) in a mixture of $\mathrm{U}_{3} \mathrm{O}_{8}$-Al sandwiched between two sheets of Al-6061. The heat produced in this pressurized light water-cooled and -moderated reactor is removed by the down flow of cooling water and is dissipated through heat exchangers to a cooling tower. The control elements, located in the annulus just outside of fuel elements, are thin metallic cylinders that contain europium and tantalum sections. A large cylinder of beryllium metal divided into three separate concentric cylinders surrounds the fuel and control elements and is used as a neutron reflector. The three reflector pieces are referred to as the removable Be reflector (RB), the semi-permanent Be reflector (SPB), and the permanent Be reflector (PB). A view of the 1970 configuration of HFIR at the horizontal midplane is depicted in Fig. 1.

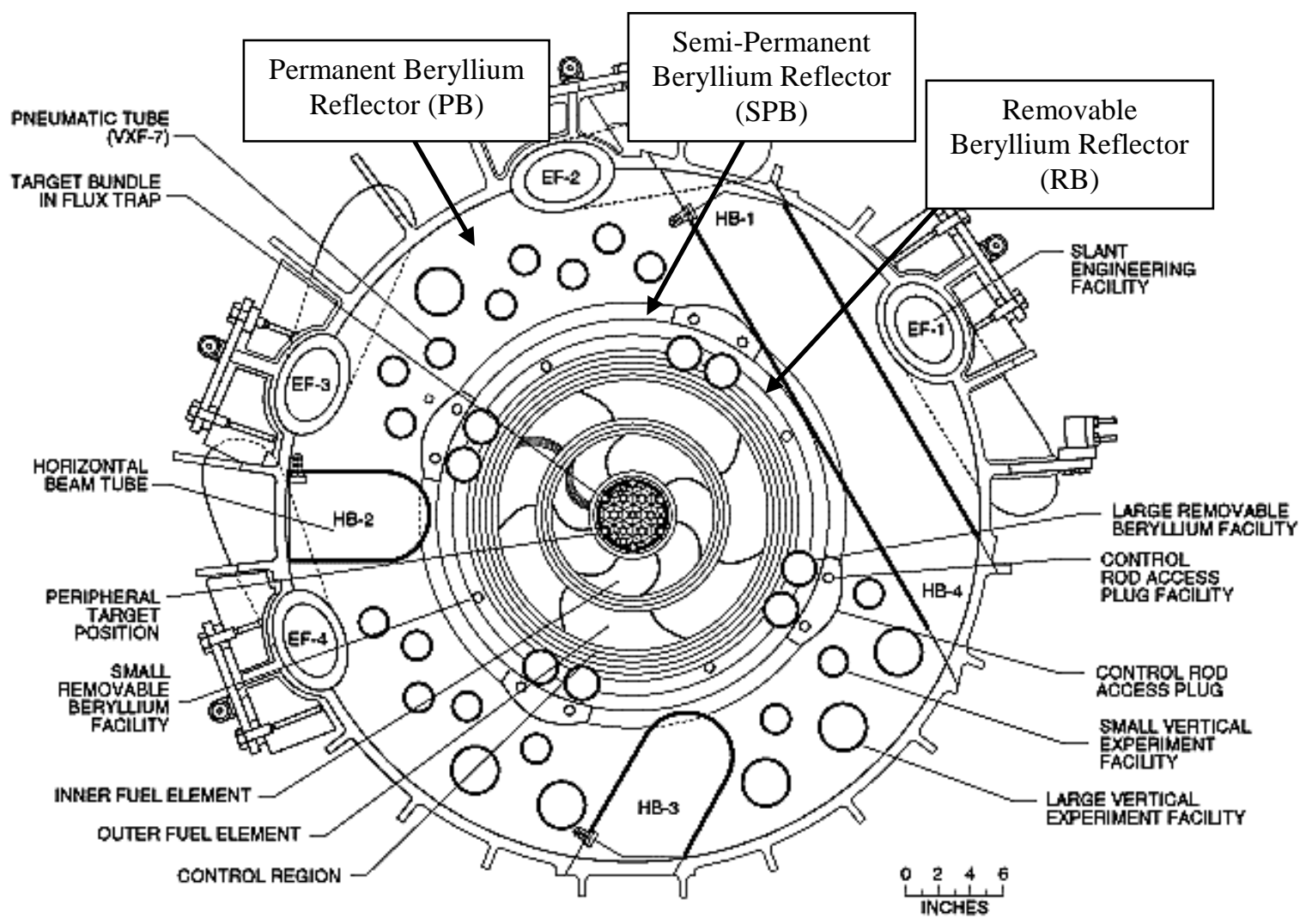

Fig. 1. Cross section of HFIR at the horizontal midplane. 


\subsection{EFFECTS OF IRRADIATION ON BERYLLIUM ${ }^{1,2,3}$}

Beryllium is a light metal ( $\rho=1.85 \mathrm{~g} / \mathrm{cc}$ ) with an atomic number of 4 and an atomic mass of $9.012182 \mathrm{amu}^{4}$ The most common isotope of beryllium is the stable ${ }^{9} \mathrm{Be}$. Beryllium is used in nuclear applications because of its relatively low neutron absorption cross section and its relatively high neutron scattering cross section. Therefore, it works well as a neutron moderator or reflector. The main disadvantage of using beryllium as a moderator or reflector is the buildup of helium-3, which is a neutron poison and can lead to swelling and mechanical property changes. Beryllium reflectors must be changed out periodically due to the internal stresses that are caused by swelling.

When ${ }^{9} \mathrm{Be}$ is irradiated by neutrons above $\sim 1 \mathrm{MeV}$, it undergoes $(\mathrm{n}, \alpha)$ and $(\mathrm{n}, 2 \mathrm{n})$ reactions. ${ }^{1}{ }^{9} \mathrm{Be}$ can also undergo $(n, \gamma)$ reactions when irradiated by thermal neutrons. The main type of reaction that causes beryllium poisoning is the $(n, \alpha)$ reaction that leads to the buildup of ${ }^{6} \mathrm{Li}$ and ${ }^{3} \mathrm{He}$, two isotopes that have very large thermal absorption cross sections. Thus, a negative reactivity is introduced in the beryllium reflector, which has to be accounted for in order to accurately predict control element startup positions. The main beryllium nuclear reaction chain equations that govern the transmutations and lead to poisoning effects are listed below:

$$
\begin{array}{lc}
{ }_{4}^{9} \mathrm{Be}+{ }_{0}^{1} n(1-2 \mathrm{MeV}) \stackrel{20 \mathrm{mb}}{\longrightarrow}{ }_{2}^{6} \mathrm{He}+{ }_{2}^{4} \mathrm{He} & \text { Eq. } 1 \mathrm{a} \\
{ }_{4}^{9} \mathrm{Be}+{ }_{0}^{1} n(2-4 \mathrm{MeV}) \stackrel{85 \mathrm{mb}}{\longrightarrow}{ }_{2}^{6} \mathrm{He}+{ }_{2}^{4} \mathrm{He} & \text { Eq. } 1 \mathrm{~b} \\
{ }_{4}^{9} \mathrm{Be}+{ }_{0}^{1} n(4-10 \mathrm{MeV}) \stackrel{10 \mathrm{mb}}{\longrightarrow}{ }_{2}^{6} \mathrm{He}+{ }_{2}^{4} \mathrm{He} & \text { Eq. } 1 \mathrm{c} \\
{ }_{2}^{6} \mathrm{He} \stackrel{0.8 s}{\longrightarrow}{ }_{3}^{6} \mathrm{Li}+\beta^{-} & \text {Eq. } 2 \\
{ }_{3}^{6} \mathrm{Li}+{ }_{0}^{1} n \text { (thermal) } \stackrel{950 b}{\longrightarrow}{ }_{2}^{4} \mathrm{He}+{ }_{1}^{3} \mathrm{H} & \text { Eq. } 3 \\
{ }_{1}^{3} \mathrm{H} \stackrel{12.33 y r}{\longrightarrow}{ }_{2}^{3} \mathrm{He}+\beta^{-} & \text {Eq. } 4 \\
{ }_{2}^{3} \mathrm{He}+{ }_{0}^{1} n(\text { thermal }) \stackrel{5327 b}{\longrightarrow}{ }_{1}^{3} \mathrm{H}+{ }_{1}^{1} p & \text { Eq. } 5
\end{array}
$$

Helium-6 is the result of the ${ }^{9} \mathrm{Be}(\mathrm{n}, \alpha)$ reaction and decays quickly into ${ }^{6} \mathrm{Li}$. The relatively large capture cross section of ${ }^{6} \mathrm{Li}$, along with the abundance of thermal neutrons in the beryllium reflector, support the production of tritium $\left({ }^{3} \mathrm{H}\right)$, a radioactive isotope of hydrogen that has a half life of 12.33 years. The daughter product of ${ }^{3} \mathrm{H}$ is ${ }^{3} \mathrm{He}$, which is produced and depleted during reactor operation. During operation, ${ }^{3} \mathrm{He}$ is produced by the decay of ${ }^{3} \mathrm{H}$ and is depleted according to the ${ }^{3} \mathrm{He}(\mathrm{n}, \mathrm{p})$ nuclear reaction. However, in a no flux environment (i.e. an outage) the ${ }^{3} \mathrm{He}$ concentration significantly increases since there is no destruction mechanism. This phenomenon must be considered, especially during long outage periods, to account for its reactivity effects on the startup of a reactor.

The above reactions (Equations 1 - 5) can be used to develop a system of differential equations by including the associated reaction rates. The reaction rate equations that govern the time evolution of ${ }^{9} \mathrm{Be},{ }^{6} \mathrm{Li},{ }^{3} \mathrm{H}$, and ${ }^{3} \mathrm{He}$ are listed below: 


$$
\begin{aligned}
& \frac{d N_{B e}(r, t)}{d t}=-N_{B e}(r) \int \varphi(r, E, t) \sigma_{B e(n, \alpha)}(E) d E-N_{B e}(r) \int \varphi(r, E, t) \sigma_{B e(n, 2 n)}(E) d E- \\
& N_{B e}(r) \int \varphi(r, E, t) \sigma_{B e(n, \gamma)}(E) d E \\
& \frac{d N_{L i}(r, t)}{d t}=N_{B e}(r, t) \int \varphi(r, E, t) \sigma_{B e(n, \alpha)}(E) d E-N_{L i}(r, t) \int \varphi(r, E, t) \sigma_{L i(n, \alpha)}(E) d E- \\
& N_{L i}(r, t) \int \varphi(r, E, t) \sigma_{L i(n, p)}(E) d E-N_{L i}(r, t) \int \varphi(r, E, t) \sigma_{L i(n, \gamma)}(E) d E \\
& \frac{d N_{T}(r, t)}{d t}=N_{L i}(r, t) \int \varphi(r, E, t) \sigma_{L i(n, \alpha)}(E) d E+N_{H e}(r, t) \int \varphi(r, E, t) \sigma_{H e(n, p)}(E) d E-\lambda_{T} N_{T}(r, t)
\end{aligned}
$$

$$
\frac{d N_{H e}(r, t)}{d t}=-N_{H e}(r, t) \int \varphi(r, E, t) \sigma_{H e(n, p)}(E) d E-N_{H e}(r, t) \int \varphi(r, E, t) \sigma_{H e(n, \alpha)}(E) d E+
$$

$$
\lambda_{T} N_{T}(r, t)
$$

In Equations 6 - 9, the subscripts $\mathrm{Be}, \mathrm{Li}, \mathrm{T}$, and He refer to the ${ }^{9} \mathrm{Be},{ }^{6} \mathrm{Li},{ }^{3} \mathrm{H}$, and ${ }^{3} \mathrm{He}$ isotopes, respectively. $\mathrm{N}, \varphi, \sigma$, and $\lambda$ stand for atomic concentration, neutron flux, microscopic cross section, and decay constant, respectively. The atomic concentrations are dependent on location and time, while the flux is dependent on location, energy, and time and the microscopic cross sections are dependent only on energy. The total microscopic cross sections of the four isotopes of interest as a function of energy are illustrated in Fig. 2. The cross section data were taken from Reference 5 and are evaluated at $300 \mathrm{~K}$.

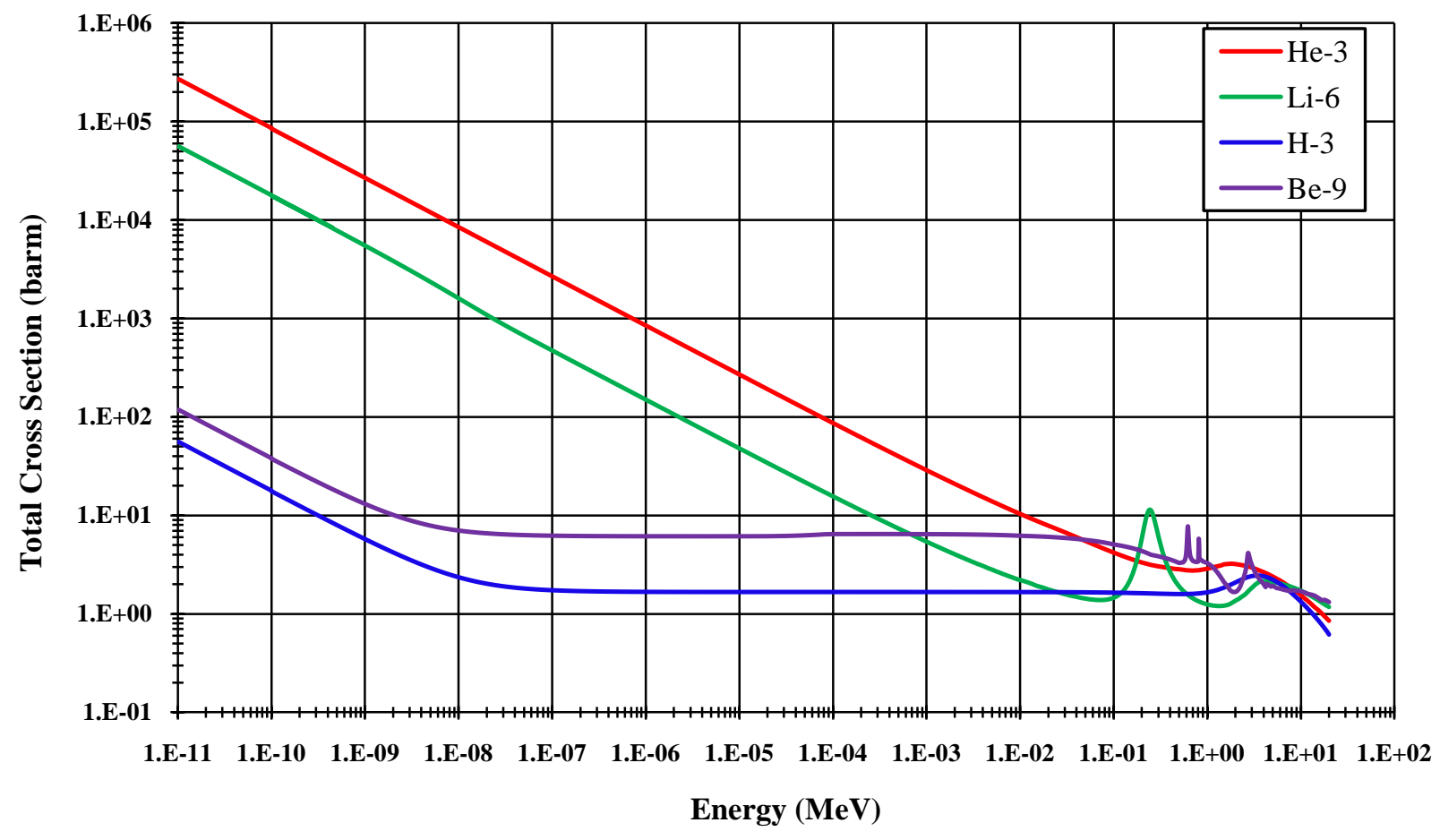

Fig. 2. Beryllium and reflector poison cross section data (ENDF/B-VII, pendfb, 300K). 


\subsection{CURRENT ESCCEP METHODOLGY}

Prior to the startup of each HFIR fuel cycle, the estimated symmetrical critical control element position (ESCCEP) is calculated. The ESCCEP is the estimated balanced control element withdrawn position for which the reactor is critical. The procedure for calculating the ESCCEP is based on comparing the reactivity difference between the cycle of interest and a reference cycle, which is typically the cycle prior to the cycle of interest. Between cycle reactivity differences occur from differences in ${ }^{3} \mathrm{He}$ and ${ }^{6} \mathrm{Li}$ content in the beryllium reflector, fuel worth, cylinder and plate burn-up, cylinder and plate ${ }^{182}$ Ta content, equilibrium RB poisons, and experimental loadings. The reactivity differences calculated for each of these categories are then converted into $\Delta \mathrm{R}$ values, which are the change in symmetrical critical control element position (inches) from the reference cycle to the cycle of interest for each category. The sum of the $\Delta \mathrm{R}$ values is added to the reference cycle's actual symmetrical critical control element position (ASCCEP) to obtain the ESCCEP for the cycle of interest.

The current methodology used to calculate the change in symmetrical critical control element position due to the ${ }^{3} \mathrm{He}$ and ${ }^{6} \mathrm{Li}$ content in the beryllium reflector from a reference cycle to the cycle of interest, $\Delta \mathrm{R}$, was derived from Reference 6. The calculation is performed in Section 6.8 of Research Reactors Division (RRD) ESCCEP calculation procedure and is described below. The $\Delta \mathrm{R}$ for poison buildup in the reflector, $\Delta \mathrm{R} 8$, is calculated by subtracting the $\Delta \mathrm{R}$ from the reference cycle, $\Delta \mathrm{R}_{\mathrm{r}}$, from the $\Delta \mathrm{R}$ from the current cycle, $\Delta \mathrm{R}_{\mathrm{c}}$.

a. Current Cycle

The reflector is new at start of cycle $\Delta \mathrm{R}=0.0$

The reflector has one or more cycles of irradiation.

$\mathrm{Td}_{\mathrm{c}}=\underline{\mathrm{t}}_{\mathrm{c}}$ days (the decay time on the reflector)

$\Delta \mathrm{R}_{\mathrm{c}}=\underline{\underline{\mathrm{t}}} \mathrm{c} * 0.0047$ (6.8a)

b. Reference Cycle

The reflector is new at start of cycle $\Delta \mathrm{R}=0.0$

The reflector has one or more cycles of irradiation.

$\mathrm{Td}_{\mathrm{r}}=\underline{\mathrm{t}}_{\underline{\mathrm{r}}}$ days (the decay time on the reflector)

$\Delta \mathrm{R}_{\mathrm{r}}=\underline{\mathrm{t}}_{\underline{r}} * 0.0047(6.8 \mathrm{~b})$

c. $\quad \Delta \mathrm{R}$ Current Cycle

$\underline{\Delta \mathrm{R}_{\underline{c}}}$ inches (6.8a)

$\Delta \mathrm{R}$ Reference Cycle

$\underline{\Delta \mathrm{R}_{\mathrm{r}}}$ inches (6.8b)

$\Delta \mathrm{R} 8=(6.8 \mathrm{a})-(6.8 \mathrm{~b})=$

$\underline{\Delta R}$ inches (6.8c)

\subsection{HFIR CYCLE 408 - RESTART FOLLOWING A LONG OUTAGE}

HFIR cycle 407 ended on December 14, 2005 and cycle 408 began on May 13, 2007. The 484 day outage was due to the conversion of horizontal beam tube number four from a 30 -m small angle neutron scattering facility to a high performance hydrogen cold source. The ESCCEP for the startup of cycle 408 was 18.656 inches. During the startup of cycle 408 the operators noticed that the difference between the estimated and actual symmetrical positions exceeded $\$ 1.55$ and thus the reactor was shutdown. Following the scram, the ESCCEP was reexamined and it was determined that the reactivity attributed to shutdown ${ }^{3} \mathrm{He}$ poison was too large. The revision 1 of the cycle 408 ESCCEP (C-HFIR-2007-035, Ref. 7) utilized another method of estimating the ${ }^{3} \mathrm{He}$ poison effect, 
which was developed in Reference 8 for cycle 383. The revised ESCCEP for cycle 408 was 18.100 inches. The initial $\Delta \mathrm{R}$ due to ${ }^{3} \mathrm{He}$ poisoning was 1.5259 and the revision predicted a $\Delta \mathrm{R}$ due to ${ }^{3} \mathrm{He}$ poisoning of 0.970 inches, a reduction of 0.556 inches. The actual symmetrical critical control element position (ASCCEP) for cycle 408 was 18.090 inches. The method used to update the poisoning effect was:

$$
\Delta R=\left(\frac{\text { Be Exposure }}{\text { Reference Be Exposure }}\right)\left(\frac{0.0047}{\lambda_{H e^{3}}}\right)\left(1-e^{-\lambda_{H e} 3 \times t_{d}}\right)
$$

In Eq. 10, beryllium exposure is expressed in MWd and 0.0047 is the current procedure's slope (inches / days of decay) that estimates the $\Delta \mathrm{R}$ as a function of days of decay between cycles. The decay constant of tritium, $\lambda_{\mathrm{He} 3}=0.000154$ days $^{-1}$, and the decay time of the outage, $\mathrm{t}_{\mathrm{d}}$ (days), are also used to calculate the $\Delta \mathrm{R}$ in Eq. 10.

This method did predict the symmetric critical control element position well, but it includes many assumptions including:

- relative ${ }^{6} \mathrm{Li}$ concentration to ${ }^{9} \mathrm{Be}$ concentration equal to $\frac{\varphi_{\text {fast }} \sigma_{B e}}{\varphi_{t h} \sigma_{L i}}$

Where $\varphi_{\text {fast }}$ and $\varphi_{\text {th }}$ are the fast and thermal fluxes, respectively, and $\sigma_{\mathrm{Be}}$ and $\sigma_{\mathrm{Li}}$ are the microscopic cross sections for beryllium and lithium, respectively.

- starting with the saturation concentration of ${ }^{6} \mathrm{Li}$

- treating the cyclic reactor operation as continuous at a slightly reduced power

- tritium produced in reflector at any time is proportional to its exposure

- all tritium produced remains within the reflector

- $\quad$ initial tritium level at which ${ }^{3} \mathrm{He}$ production begins during a shutdown interval is proportional to the exposure of the beryllium

- the reactivity effect of the increased ${ }^{3} \mathrm{He}$ is proportional to its increase in concentration

- using a normalization factor that includes the 0.0047 inches/day factor used in the current ESCCEP methodology

Although the assumptions are valid, the process is rather complex and still utilizes data calculated for cycles operating at a full power of $100 \mathrm{MW}$. The incorrect prediction of the ASCCEP for cycle 408 due to an incorrect prediction in the ${ }^{3} \mathrm{He}$ poisoning effect is the motivation behind developing a better ${ }^{3} \mathrm{He}$ poisoning correlation in this study. 


\section{COMPUTATIONAL MODEL DEVELOPMENT}

Version 6 of the Standardized Computer Analysis for Licensing Evaluation (SCALE) ${ }^{9}$ code system was utilized for this study. SCALE was developed and is maintained by Oak Ridge National Laboratory (ORNL) under contract with the Department of Energy (DOE) and the Nuclear Regulatory Commission (NRC). The SCALE code is used to perform reactor physics, criticality safety, radiation shielding, and spent fuel characterization calculations. The 238 group ENDF/B-VII release 0 library was utilized in the analyses reported here.

Depletion calculations were performed using the TRITON control module. In particular, the t5depl sequence was utilized for 3-D depletion. This sequence couples the three-dimensional (3-D) Monte Carlo transport code KENO V.a and the depletion code ORIGEN. A current 3-D MCNP model of HFIR (Reference 10) was converted into a simplified 3-D SCALE/KENO V.a model.

The TRITON module in SCALE does not have a restart capability. In order to calculate the poisoning effect of ${ }^{3} \mathrm{He}$ as a function of time, TRITON was executed with multiple decay times following the 20 cycle irradiation sequence. As explained in more detail on the following pages, 20

cycles were simulated to allow ${ }^{3} \mathrm{He}$ and ${ }^{6} \mathrm{Li}$ to buildup and then multiple decay times were simulated in order to observe the poisoning effect as a function of outage time. Atomic densities within the beryllium reflector at each decay step were then passed to "standalone" $\mathrm{k}_{\mathrm{eff}}$ calculations. These calculations were performed with the same KENO-V.a model as used in the TRITON sequence but with the CSAS5 module. Although one more step in TRITON could have been simulated to calculate the necessary data $\left(\mathrm{k}_{\mathrm{eff}}\right)$, standalone $\mathrm{k}_{\mathrm{eff}}$ calculations were performed in CSAS5 so more histories could be simulated. The depletion calculations utilized 10 million histories per transport calculation while the CSAS5 calculations utilized 50 million histories to obtain better statistics. A check case was run for a couple depletion steps with 50 million histories and was compared to the 10 million history case and negligible differences were observed in the beryllium composition.

The standalone $\mathrm{k}_{\mathrm{eff}}$ calculations were performed using the CSAS5 control module, which is a criticality safety analysis sequence. The CENTRM/PMC methodology was used for cross section processing. CENTRM uses a combination of pointwise and multigroup nuclear data to solve the Boltzmann Transport Equation to compute continuous-energy neutron spectra, and PMC generates problem-dependent multigroup cross sections from an existing AMPX multigroup cross section library, a pointwise nuclear data library, and a pointwise neutron flux file produced by the CENTRM continuous-energy transport code.

\section{$2.1 \quad$ TRITON INPUT}

For all of the TRITON cases run in this analysis, the reflector regions were depleted by flux while the material compositions of all the other regions remained constant. The removable beryllium reflector (RB) is modeled by dividing it into 3 radial regions and the material numbers corresponding to the 3 radial regions are 411, 412, and 413 (innermost to outermost regions). The semi-permanent beryllium reflector (SPB) is modeled by dividing it into 1 radial region and material number 414 corresponds to that region. The permanent beryllium reflector (PB) is modeled by dividing it into 7 radial regions and the material numbers corresponding to the 7 radial regions are $415-421$ (innermost to outermost regions).

\subsubsection{Cross Section Processing Part of TRITON}

The atomic densities and reactor dimensions were taken from Reference 10 and were used to create a TRITON/KENO V.a model. The T5-DEPL sequence was specified in TRITON, which invokes the CRAWDAD, BONAMI, WORKER, CENTRM, PMC, KENO V.a, KMART, COUPLE, ORIGEN, and OPUS modules. Three-dimensional Monte Carlo transport calculations were performed via KENO V.a and 3-D, multi-material depletions were executed using burn-up-dependent 
cross section preparation. Cross sections were processed using the BONAMI and CENTRM/PMC modules and KMART collapsed the cross sections into the three-group format needed by COUPLE and ORIGEN. COUPLE is used to update the ORIGEN cross section library and ORIGEN performs the depletion calculations.

\subsubsection{Conversion of MCNP HFIR Model to a KENO V.a Model}

The HFIR cycle 400 model is based on a 3-D MCNP model, named HFV4.0, and accurately represents the HFIR as loaded in cycle $400 .{ }^{10}$ HFV4.0 is based on an older model that was previously developed at ORNL. These models are quality-controlled and have been set up such that the user can modify the input cards to reflect any changes to the model or future experimental rearrangements such as the flux trap loading. The MCNP model is broken up into six major regions (parts), as follows:

- Region 1: Flux Trap Target Region (FTT)

- Region 2: Inner Fuel Element Region (IFE)

- Region 3: Outer Fuel Element Region (OFE)

- Region 4: Control Element Region (CE)

- Region 5: Removable Beryllium Reflector Region (RB)

- Region 6: Permanent Beryllium Reflector Region (PB)

For a more detailed description of the MCNP model, refer to Reference 10.

The SCALE model was created by extracting the material compositions (atomic densities) and dimensions from HFV4.0 and inserting them into KENO V.a, a Monte Carlo criticality program, via the flexible data input. The KENO V.a model developed for this study is a simplified 3-D model of HFIR in comparison to the MCNP model because physics parameters for the core region, e.g. local power densities, are not needed. For this study, only an accurate representation of the flux magnitude and spectra leaking from the core to the reflector is needed. The KENO V.a model was constructed using the inside out method and concentric cylindrical geometry. That is, the model was constructed by describing cylindrical regions from the core centerline (the flux trap) to the outermost region (the water reflector). The radial dimensions of the pertinent regions of HFIR, as modeled in both MCNP and KENO V.a are listed in Table 1.

Table 1. Radial regions of HFIR.

\begin{tabular}{l|c|c}
\hline \multicolumn{1}{c|}{ Region } & Inner Radius (cm) & Outer Radius (cm) \\
\hline Flux Trap & 0 & 6.43 \\
\hline IFE Side Plate & 6.43 & 13.45 \\
\hline IFE Active Element & 7.14 & 12.60 \\
\hline OFE Side Plate & 14.29 & 21.75 \\
\hline OFE Active Element & 15.13 & 20.98 \\
\hline Control Elements & 21.75 & 23.97 \\
\hline Removable Reflector & 23.97 & 30.17 \\
\hline Permanent Reflector & 30.17 & 54.61 \\
\hline Water Reflector & 54.61 & 119.38 \\
\hline Pressure Vessel & 119.38 & 121.92 \\
\hline
\end{tabular}




\subsubsection{Flux Trap Target Region (FTT)}

Thirty-seven experimental sites are provided in the flux trap target region. Of the 37 sites, 31 of them are located in the interior of the basket and the other 6, referred to as peripheral target positions (PTPs), are located at the outer radial edge of the basket. One of the interior sites houses a hydraulic tube (HT), which allows specimens requiring short irradiation exposures to be inserted and removed during reactor operation. The cycle 400 flux trap contained 7 solid aluminum targets, 21 shrouded aluminum targets, 2 stainless steel targets, and multiple specimens in the HT and PTPs. This loading is typical of current operations; however, during earlier operation of HFIR, numerous target rods containing transuranic elements (typically ${ }^{242} \mathrm{Pu}$ ) were located in the flux trap for californium production. Today, curium targets are transmuted for californium production.

The 37 rods modeled in HFV4.0 contained target, clad, shroud, and coolant regions. These regions were homogenized in the KENO V.a model such that one region was defined for each of the 37 rods. The outer radius of the interior target rods and PTPs are $0.835 \mathrm{~cm}$ and 1.00076 $\mathrm{cm}$, respectively. HFV4.0 models the aluminum ring that surrounds the targets, but the KENO V.a model was simplified by homogenizing the water inside the basket with the aluminum ring. An x-y cross section of the flux trap as modeled in MCNP and KENO V.a can be compared to the flux trap loading diagram in Figures 3, 4, and 5.

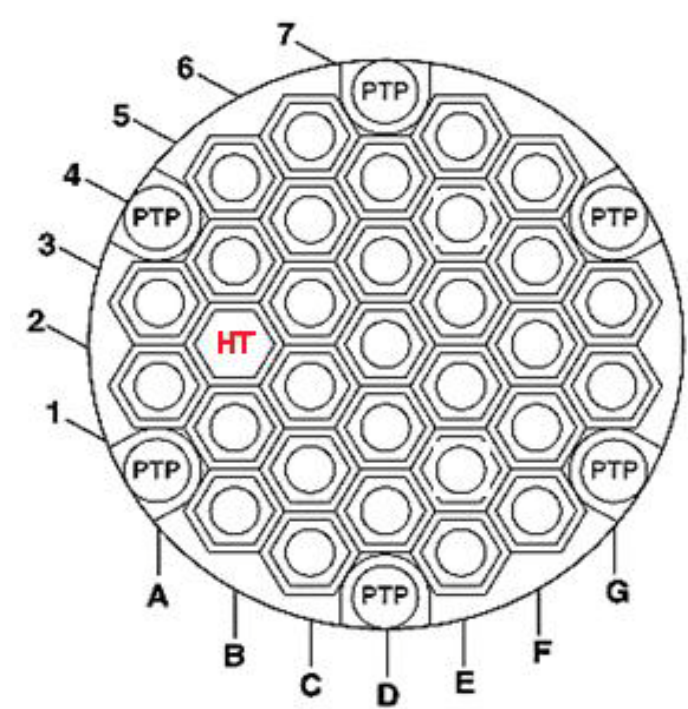

Fig. 3. Flux trap target loading diagram.

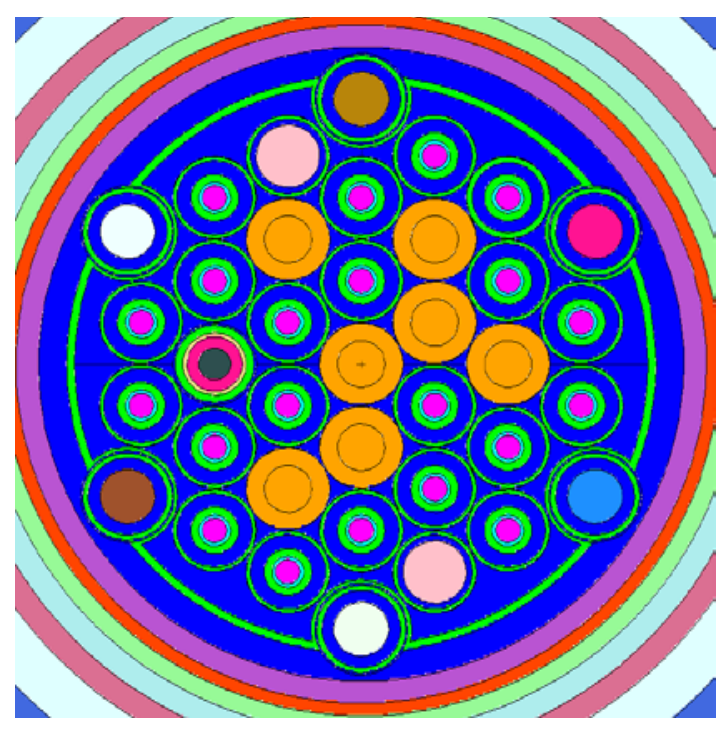

Fig. 4. Cross section of MCNP model across the flux trap.

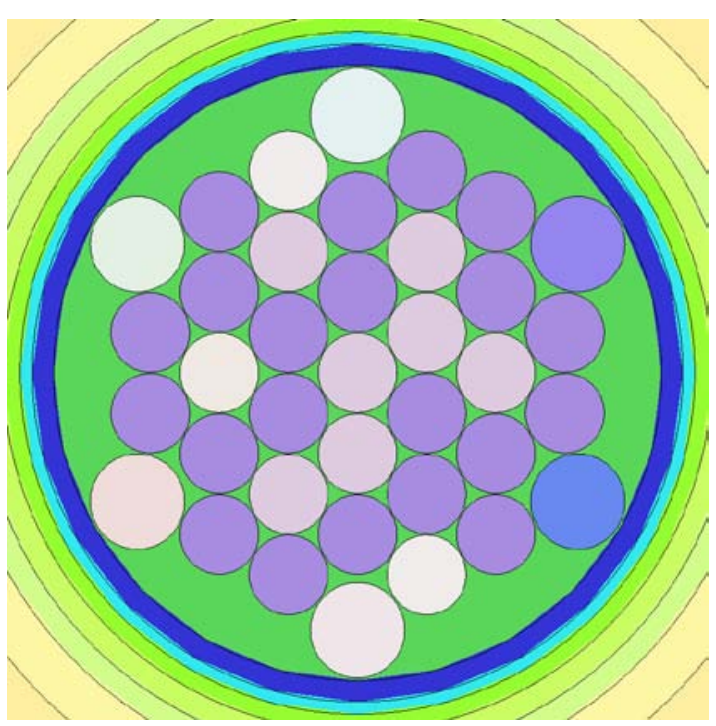

Fig. 5. Cross section of SCALE model across the flux trap. 


\subsubsection{Fuel Elements (FEs)}

The two fuel elements are concentric annuli designated the inner fuel element (IFE) and the outer fuel element (OFE). The IFE is composed of 171 involute fuel plates, each of which contains 15.18 grams of ${ }^{235} \mathrm{U}$ and the OFE is composed of 369 involute fuel plates with 18.44 grams of ${ }^{235} \mathrm{U}$ per fuel plate. Each of the fuel plates contain $\mathrm{U}_{3} \mathrm{O}_{8}$ - $\mathrm{Al}\left(\sim 93 \mathrm{wt} . \%{ }^{235} \mathrm{U}\right)$ fuel meat embedded in Al-6061 clad. The fuel meat and burnable poison in the form of boron (only in the IFE) are non-uniformly disturbed along the arc of the involute to reduce power peaking. The $0.127 \mathrm{~cm}$ thick plates are separated by $0.127 \mathrm{~cm}$ water gaps.

The HFIR fuel elements are modeled by dividing them into radial regions of varying, spatiallyaveraged ${ }^{235} \mathrm{U}$ concentrations. These regions are created by homogenizing the fuel, the Al filler, the burnable poison (boron in IFE), the $\mathrm{Al}$ side walls, and the water in the channels between the involute fuel plates. The IFE is modeled as 8 concentric radial zones and the OFE is modeled as 9 concentric radial zones. The radial regions utilized for this analysis are listed in Table 2 and are illustrated for both the MCNP and KENO V.a models in Figures 6 and 7. The ${ }^{235} \mathrm{U}$ atomic concentration as a function of distance from the core centerline is shown in Fig. 8. The HFV4.0 model divides the fuel elements into multiple axial layers, but the KENO V.a model only uses one axial layer because fuel burn-up is not analyzed in this study (also because the FORTRAN routine in scalelib is only capable of holding 1,000,000 blocks).

Table 2. As modeled radial regions of HFIR fuel elements.

\begin{tabular}{c|c|c|c|c}
\hline \multicolumn{5}{|c}{ IFE } \\
\hline $\begin{array}{c}\text { Radial } \\
\text { Region }\end{array}$ & $\begin{array}{c}\text { Inner Radius } \\
(\mathbf{c m})\end{array}$ & $\begin{array}{c}\text { Outer Radius } \\
(\mathbf{c m})\end{array}$ & $\begin{array}{c}\text { Inner Radius } \\
(\mathbf{c m})\end{array}$ & $\begin{array}{c}\text { Outer Radius } \\
(\mathbf{c m})\end{array}$ \\
\hline 1 & 7.14 & 7.50 & 15.13 & 15.50 \\
\hline 2 & 7.50 & 8.00 & 15.50 & 16.00 \\
\hline 3 & 8.00 & 8.50 & 16.00 & 16.50 \\
\hline 4 & 8.50 & 9.50 & 16.50 & 17.50 \\
\hline 5 & 9.50 & 10.50 & 17.50 & 18.50 \\
\hline 6 & 10.50 & 11.50 & 18.50 & 19.50 \\
\hline 7 & 11.50 & 12.00 & 19.50 & 20.00 \\
\hline 8 & 12.00 & 12.60 & 20.00 & 20.50 \\
\hline 9 & - & - & 20.50 & 20.93 \\
\hline
\end{tabular}




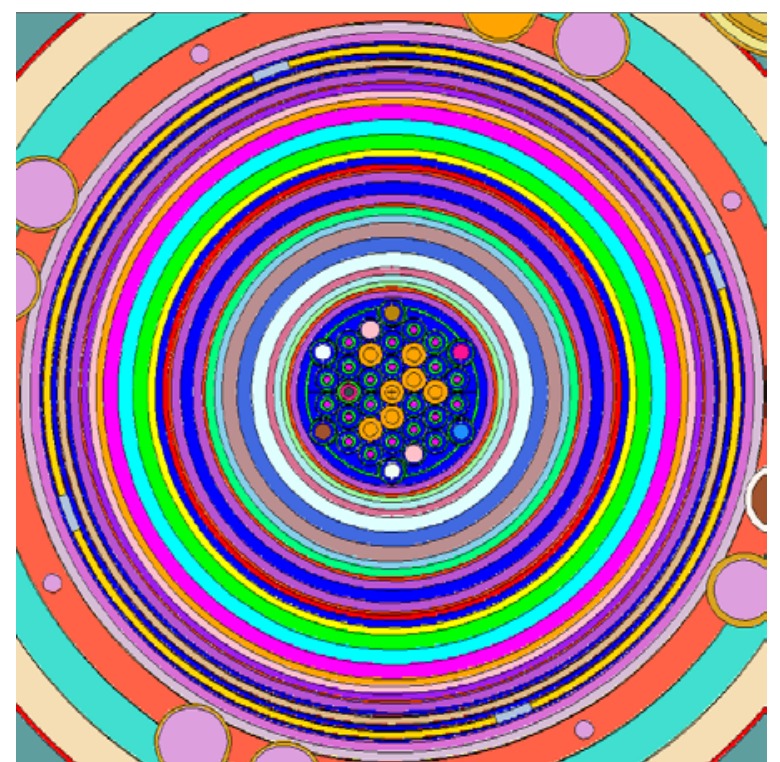

Fig. 6. Cross section of MCNP model across the flux trap and fuel elements.

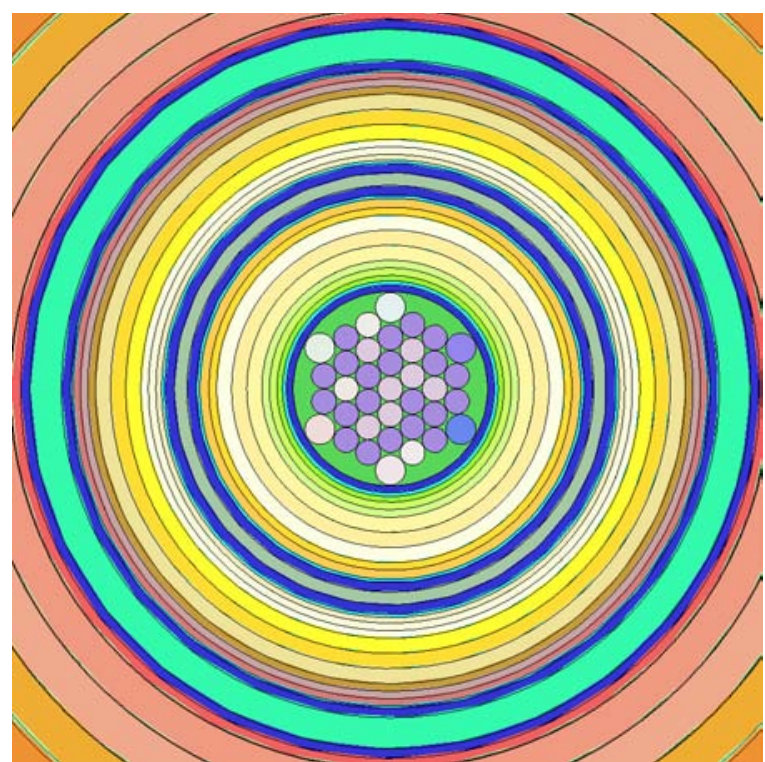

Fig. 7. Cross section of SCALE model across the flux trap and fuel elements.

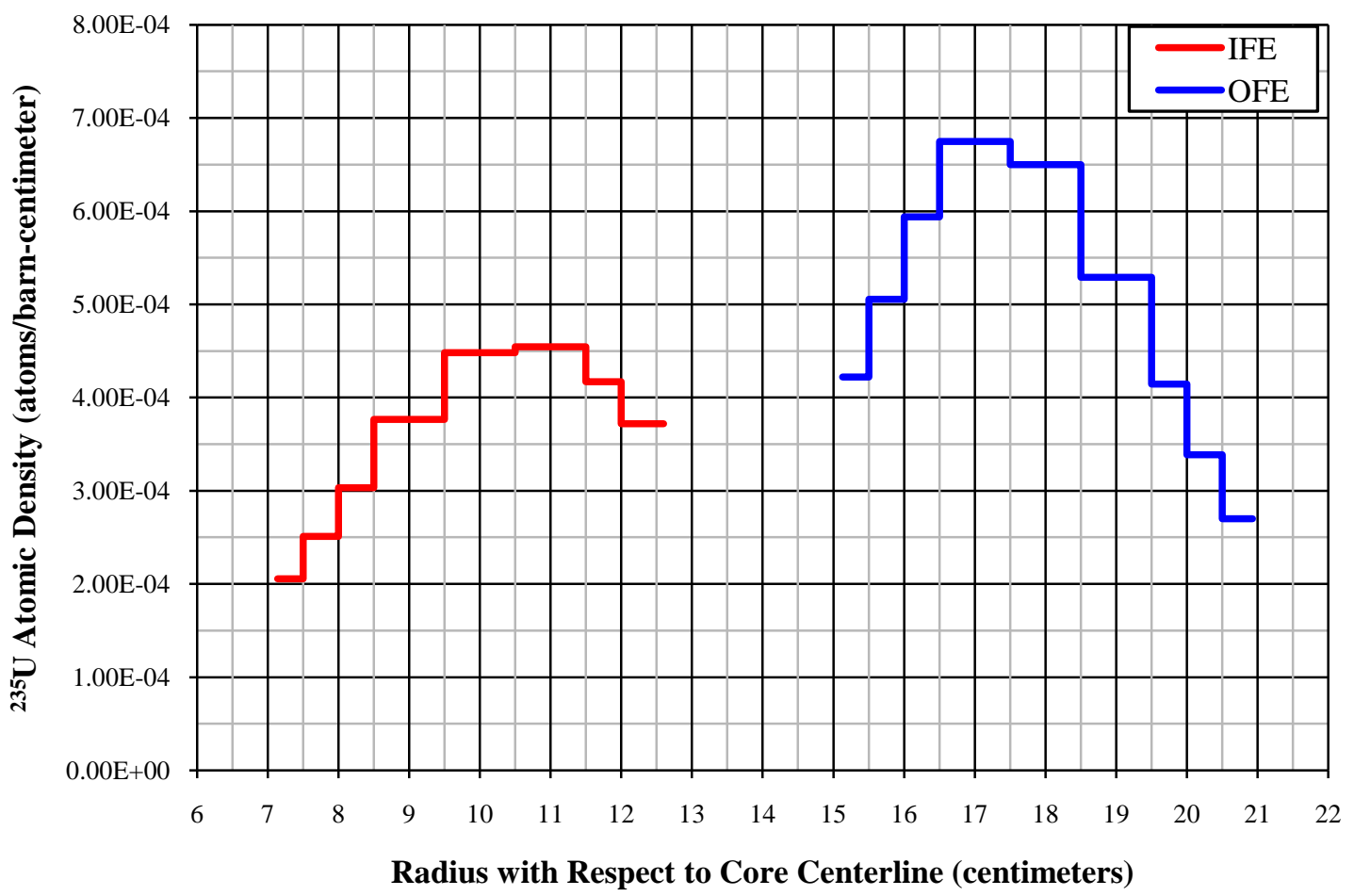

Fig. 8. Modeled ${ }^{235} \mathrm{U}$ atomic concentration distribution. 


\subsubsection{Control Elements (CEs)}

Two poison-bearing concentric control elements (CE), an inner control element and an outer control element, are located between the fuel elements and the beryllium reflector. The inner CE is a single plate in the shape of a cylinder and is used to regulate power and the outer CE is composed of four separate quadrants thereby forming four safety plates. Both elements are composed of three axial regions of different poison content: a white, grey, and black region. The white, grey, and black regions are composed of $\mathrm{Al}$, Ta- $\mathrm{Al}$, and $\mathrm{Eu}_{2} \mathrm{O}_{3}-\mathrm{Al}$, respectively.

The MCNP input explicitly represents the control elements and uses transformation cards so the user can easily adjust the symmetrical positions. Due to the complexity introduced in modeling the control elements and the fact that numerous cycles are to be modeled in this analysis and only one axial fuel and reflector region can be defined for each radial region, the control elements are not explicitly modeled in the KENO V.a model. For this analysis, the core leakage spectra and energydependent flux magnitudes are the needed physics parameters. To control reactivity (i.e. keep $\mathrm{k}_{\mathrm{eff}}$ 1.00), $3.6 \times 10^{-5}$ atoms/b-cm of ${ }^{10} \mathrm{~B}$ was mixed with the water that already exists in the control element channel (the area where reactivity is controlled). Any neutron absorbing material could have been chosen because the function of including the poison is to keep $\mathrm{k}_{\mathrm{eff}}$ very close to unity for transport calculation purposes, but ${ }^{10} \mathrm{~B}$ was chosen because homogenizing the europium and tantalum - the components of the control elements - both being resonance absorbers, could yield perturbations in the neutron leakage spectra greater than that caused by the assumption of boron in the control region. A comparison of the neutron flux spectra from MCNP and KENO V.a models is provided in Appendix A.

\subsubsection{Beryllium Reflector}

The beryllium reflector is approximately 30.5 centimeters thick and is subdivided into three regions: (1) the removable reflector (RB), (2) the semi-permanent reflector (SPB), and (3) the permanent reflector (PB). The RB has an inner and outer radius of $24.4475 \mathrm{~cm}$ and $30.25267 \mathrm{~cm}$, respectively, and is typically replaced after approximately 40 full power cycles. The SPB has an inner and outer radius of $30.32125 \mathrm{~cm}$ and $33.02 \mathrm{~cm}$, respectively, and is typically replaced after approximately 80 cycles. The PB has an inner and outer radius of $33.3375 \mathrm{~cm}$ and $54.61 \mathrm{~cm}$, respectively, and is typically replaced after approximately 135 cycles.

The beryllium reflector is used to reflect the neutrons that leak out of the fuel region back into the fuel region and is used to house numerous experimental facilities. Four small removable beryllium facilities and eight large removable beryllium facilities are located in the removable beryllium region. Four control rod access plug facilities are located in the semi-permanent beryllium reflector. Sixteen small vertical experiment facilities and six large vertical experiment facilities penetrate the permanent reflector. HFIR is equipped with four horizontal beam tubes that penetrate the permanent reflector and extend outward from the reactor core at the horizontal midplane. Two slant engineering facilities terminate at the outer periphery of the permanent reflector. A picture of the permanent beryllium reflector is shown in Fig. 9. 


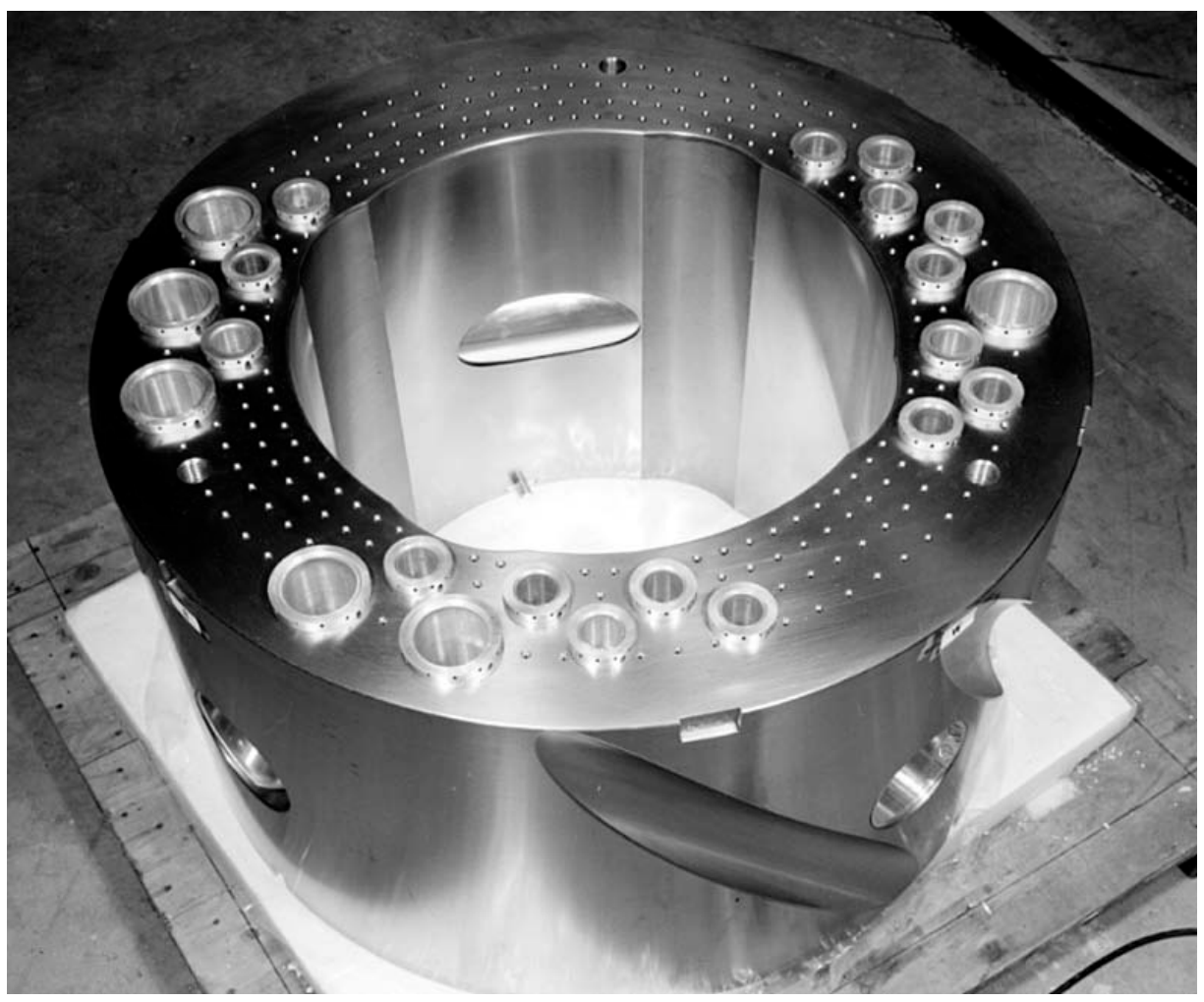

Fig. 9. Permanent beryllium reflector.

The MCNP model contains all of the experimental sites including the liners and the contents, but the beryllium reflectors in the KENO V.a model are modeled as solid concentric cylinders of $100 \%$ ${ }^{9} \mathrm{Be}$ (i.e. the experimental sites are not modeled). Since the volume fraction of the experimental sites in the beryllium reflectors is relatively small, especially in the RB and SPB where the neutron flux is the largest (in the reflector region) and thus the ${ }^{3} \mathrm{He}$ and ${ }^{6} \mathrm{Li}$ buildup is the greatest, the effects of neglecting the experimental facilities for this study are negligible. Also, the majority of the experimental facilities are typically occupied by beryllium plugs. For both the MCNP and KENO V.a models, the three reflector regions are modeled as 1 axial region, while the RB is divided into 3 radial regions, the SPB is modeled as one radial region, and the PB is divided into 7 radial regions. The beryllium reflectors, along with the rest of the HFIR core as modeled in both MCNP and KENO V.a are depicted in Figures 10, 11, 12, and 13. Figures 10 and 11 illustrate an X-z cross section of HFIR as modeled in MCNP and KENO V.a, respectively, and Figures 12 and 13 illustrate an x-y cross section of HFIR as modeled in MCNP and KENO V.a, respectively. An isometric view of the KENO V.a model of HFIR excluding the water reflector is shown in Fig. 14.

Beyond the beryllium reflector there is approximately $50 \mathrm{~cm}$ of water and then the steel pressure vessel. The outermost region modeled in the KENO V.a model was the water reflector since the neutrons arriving at the pressure vessel are very unlikely to return to the beryllium reflector or the fuel elements. 


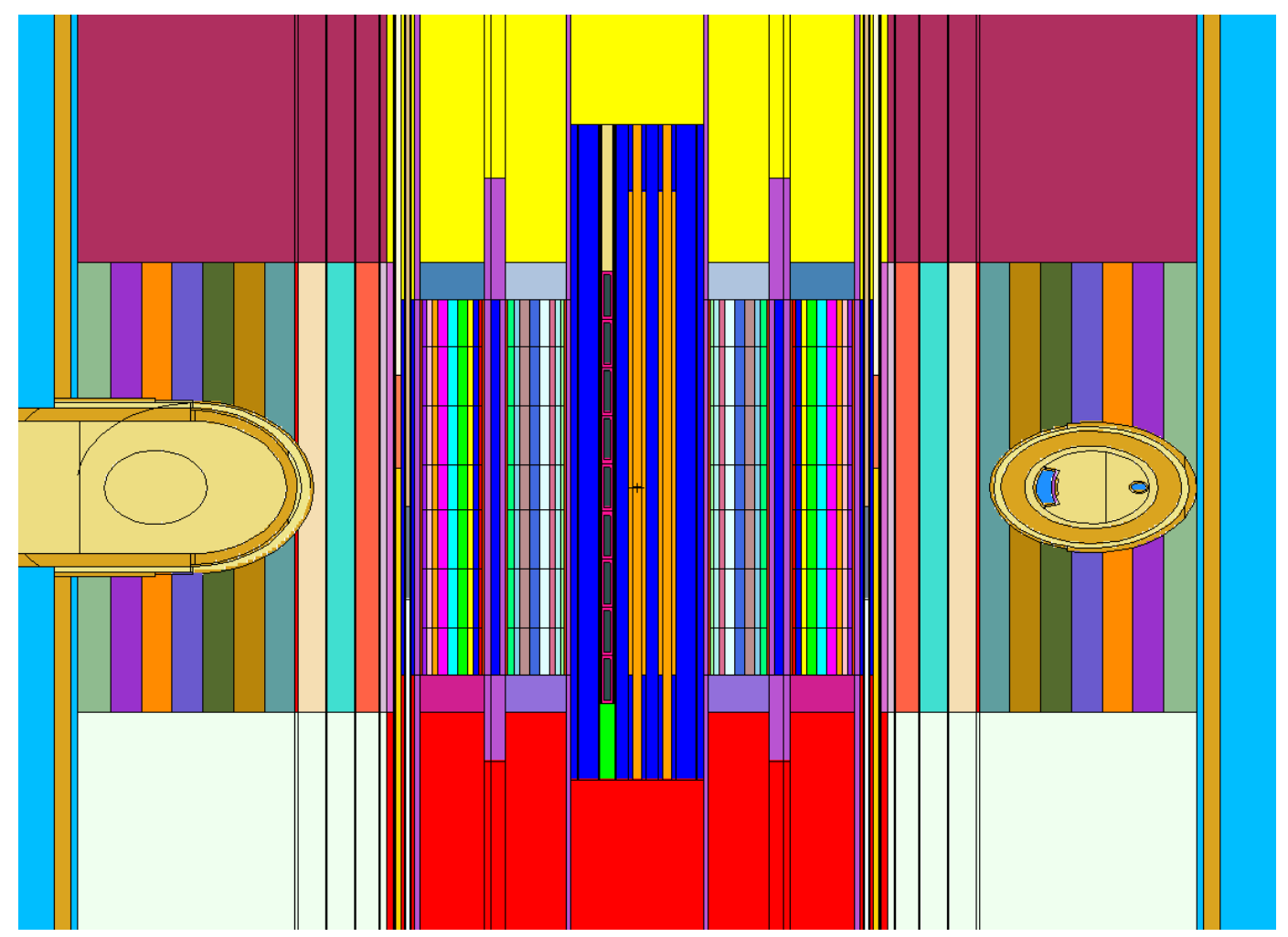

Fig. 10. $x-z$ cross section of HFIR as modeled in MCNP.

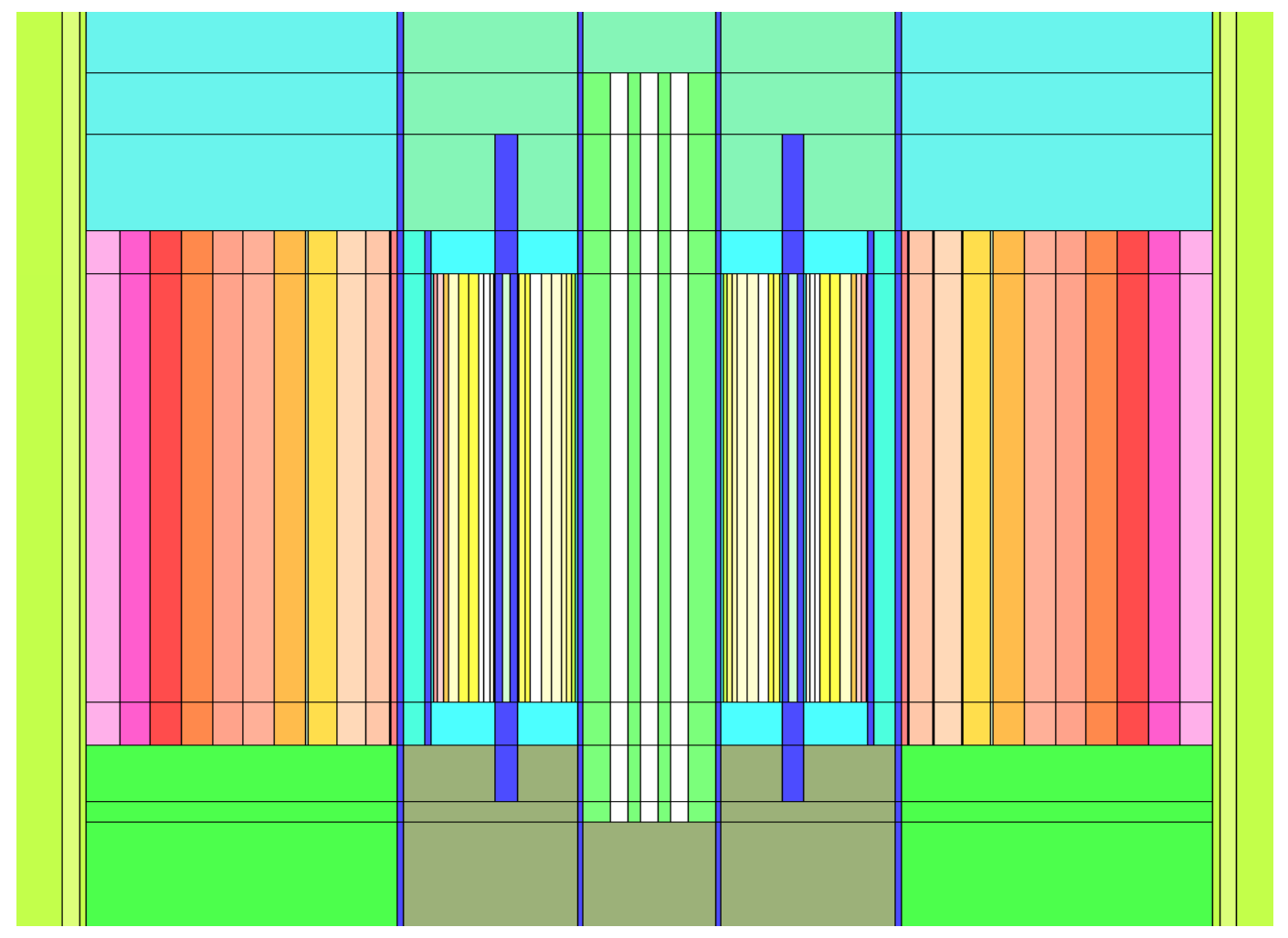

Fig. 11. $x-z$ cross section of HFIR as modeled in SCALE. 


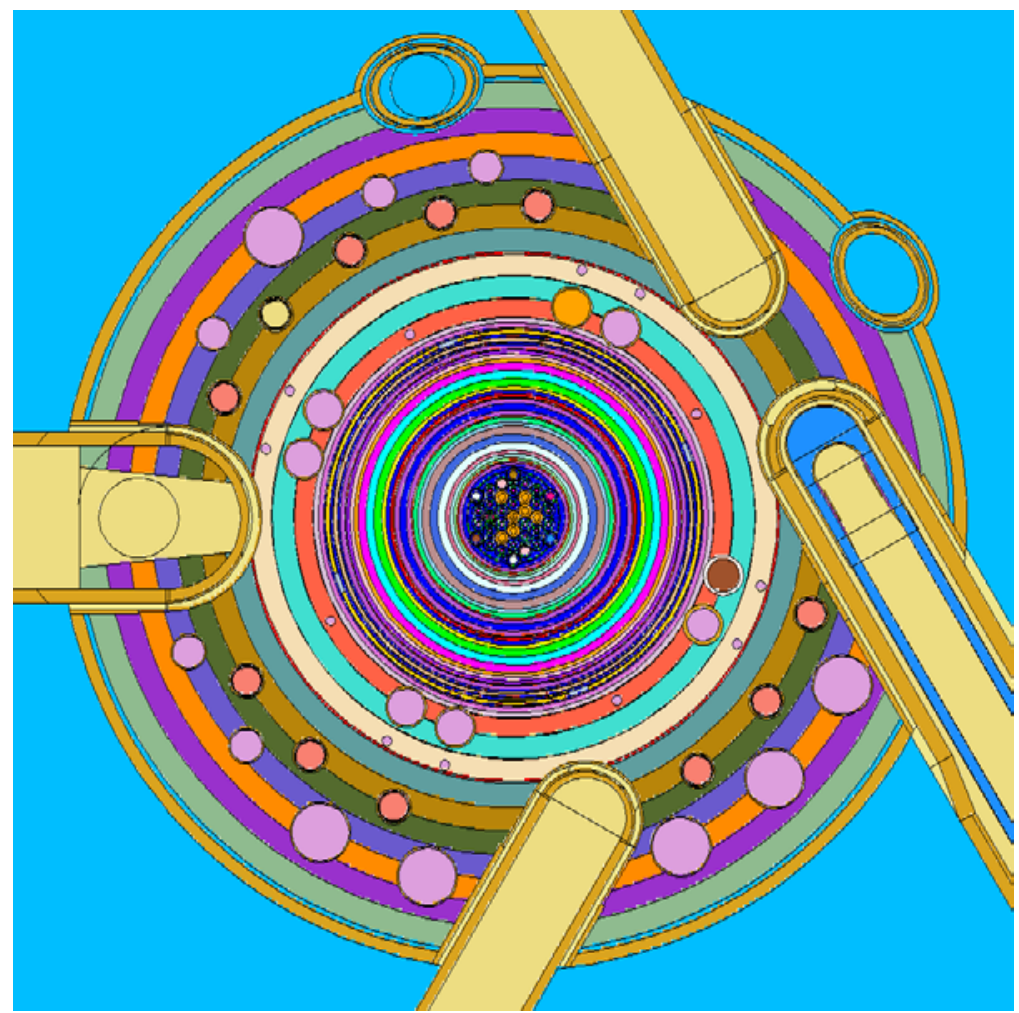

Fig. 12. Cross section of HFIR MCNP model at the horizontal midplane.

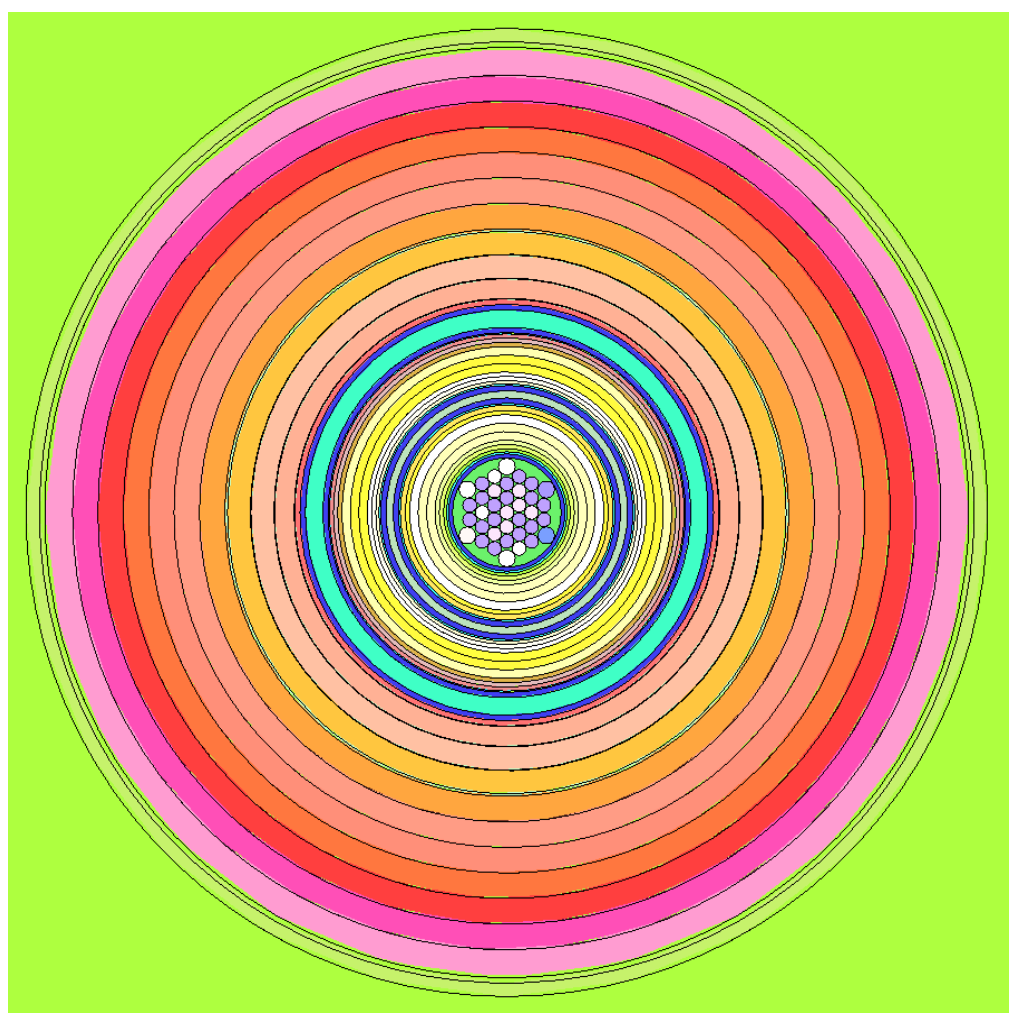

Fig. 13. Cross section of HFIR SCALE model at the horizontal midplane. 


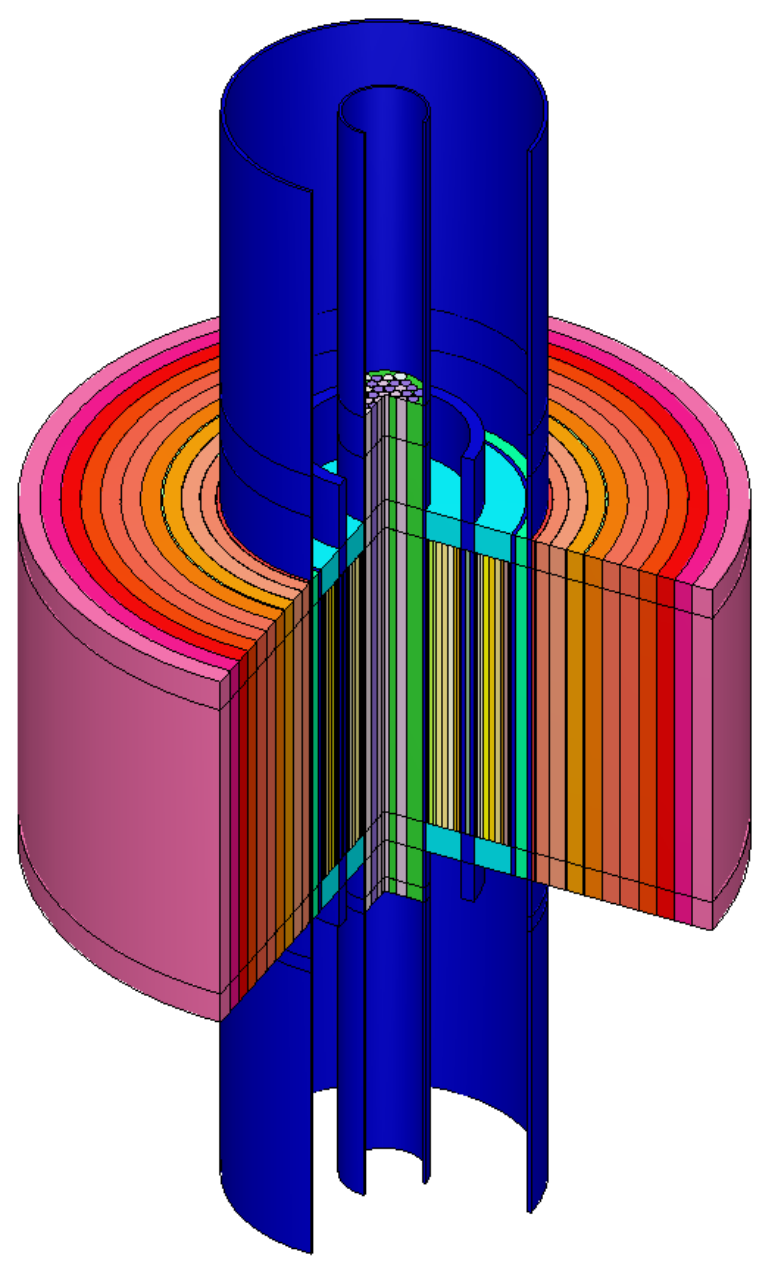

Fig. 14. Isometric view of the HFIR SCALE model.

\subsubsection{Depletion/Decay Portion of TRITON Input}

The beryllium reflector was depleted by flux while the material compositions of all the other regions remained constant. The material numbers for the removable beryllium reflector are 411,412 , and 413 and material 414 makes up the semi-permanent reflector. The material numbers for the permanent beryllium reflector are 415 - 421. The DEPLETION card was as follows:

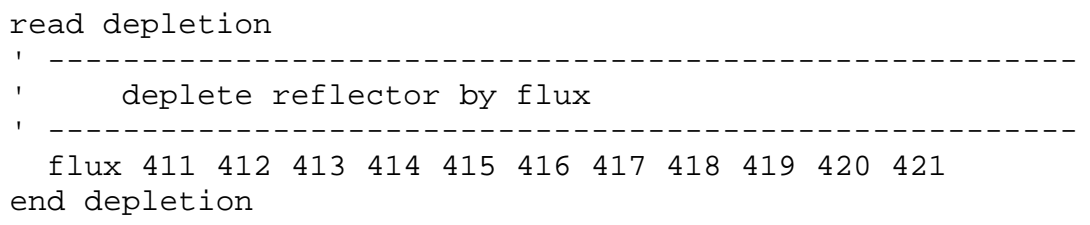

As explained in Section 3, twenty-one 25 day irradiation periods were modeled with 25 days of down time between each cycle. Following the end of the $21^{\text {st }}$ cycle, multiple decay steps were modeled, which is represented by the $\mathbf{X}$ at the end of the BURNDATA card shown below: 


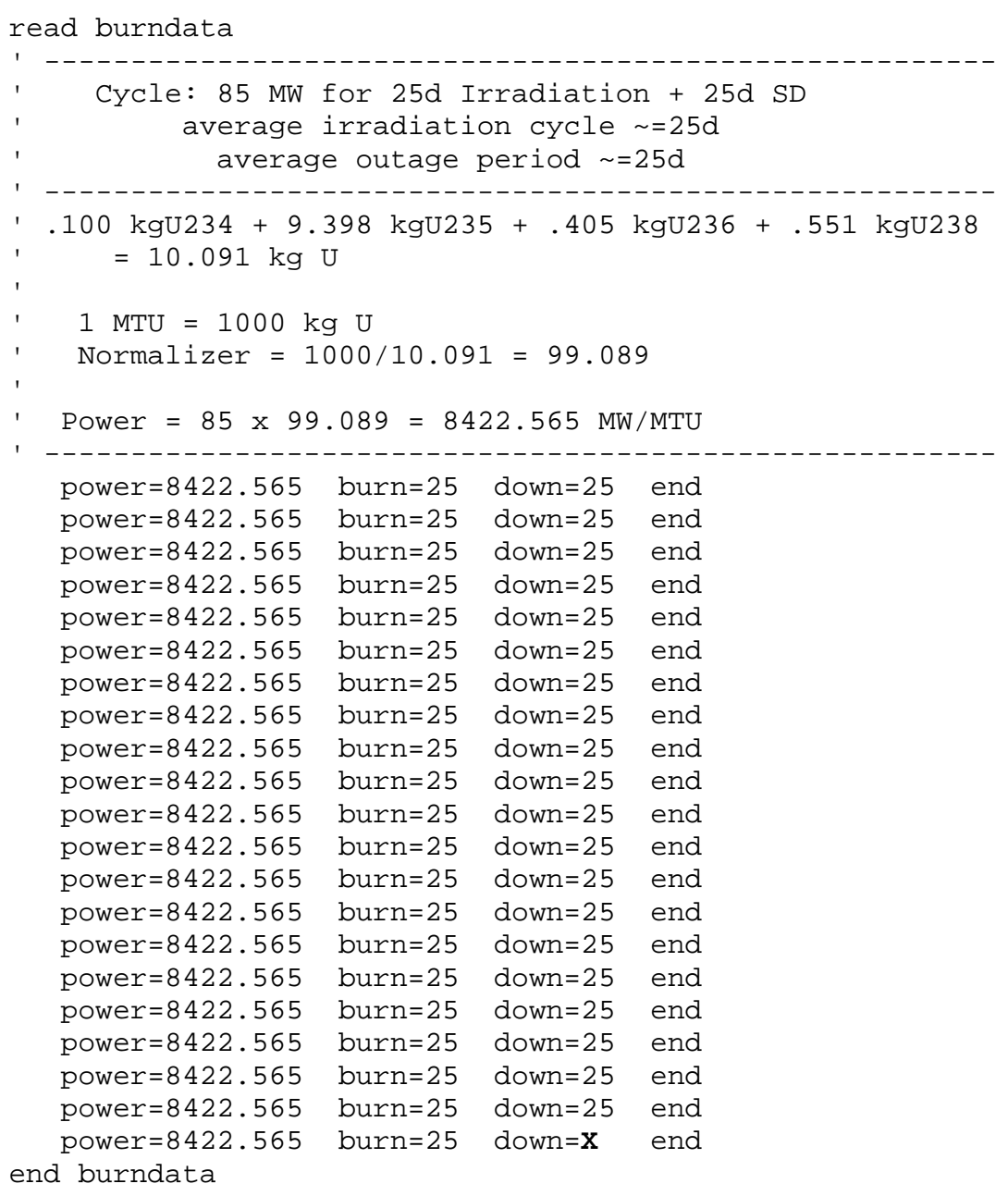

Before the final cases were run, a sample case was run to determine the initial amount of heavy metal (HM) in the problem. The output of the sample run revealed that $10.091 \mathrm{~kg}$ of HM per unit height ( $\sim 9.4 \mathrm{~kg}$ of which is ${ }^{235} \mathrm{U}$ in the fuel) was present initially and a normalization factor of 99.089 /MTHM was used to calculate the normalized power to be input in the BURNDATA card:

$$
\text { specific power }(\mathrm{MW} / \mathrm{MTHM})=85 \mathrm{MW} \text { x 99.089 } \mathrm{MTHM}^{-1}=8422.565 \mathrm{MW} / \mathrm{MTHM}
$$

For all of the depletion cases, the OPUS functional module was used to output the reflector compositions in atoms/barn-centimeter for all 11 reflector regions as generated by the ORIGEN code. After running sample cases, it was determined that 18 isotopes were present in the reflector regions following irradiation, so the SYMNUC and SORT inputs were used to list these isotopes to ease the setup of the CSAS5 input and data manipulation. The OPUS card used for this analysis is as follows:

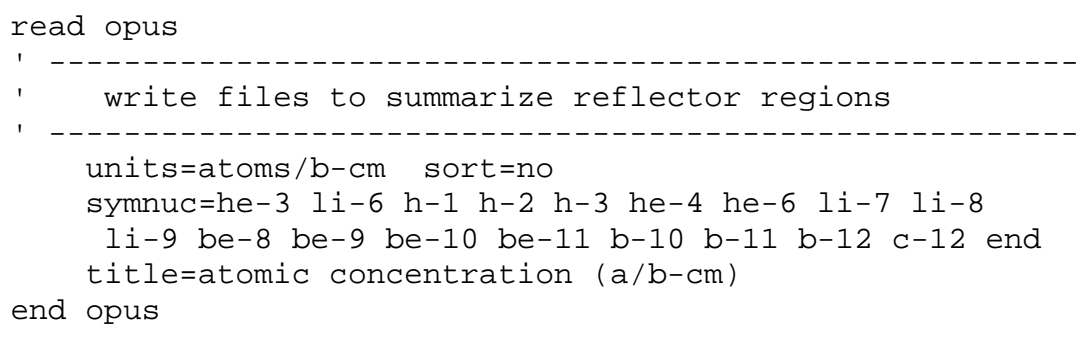


The PARAMETER card was used to specify the number of histories to run in the transport calculations. A total of 11.5 million histories were simulated at each step, which was deemed satisfactory after running test cases. Test cases utilizing up to 50 million histories were run and almost no compositional differences were observed. A total of 10,000 histories per generation and 1,150 generations with the first 150 skipped were used. The PARAMETER card was defined as follows:

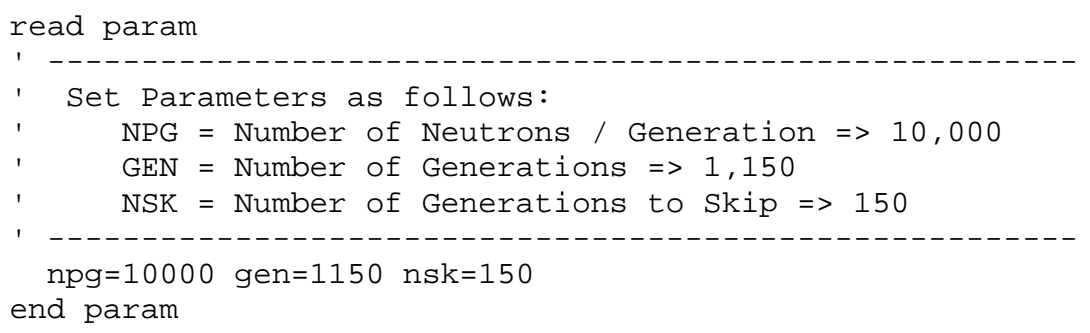

\subsection{CSAS5 INPUT}

Rather than performing one more burn up step in each of the TRITON runs to obtain the $\mathrm{k}_{\text {eff }}$ for each decay step, CSAS5 was used to perform the standalone $\mathrm{k}_{\text {eff }}$ calculations to increase the number of histories from 11.5 million to 51.5 million to obtain better statistics. The TRITON input was converted into a CSAS5 input by deleting the TRITON specific inputs and inserting the CSAS5 specific inputs and by updating the beryllium composition. Thus, the geometry and material compositions, except for the beryllium reflector region's compositions, were the same for both the CSAS5 and TRITON inputs.

PARM=CENTRM was specified, so the execution path BONAMI, CENTRM/PMC, and KENO V.a was followed. The reflector materials following the decay step defined at the end of the $21^{\text {st }}$ cycle were extracted and inserted into CSAS5 inputs. Since ENDF data are not available for ${ }^{10} \mathrm{Be}$ and ${ }^{12} \mathrm{C}$, these isotopes were omitted from the $\mathrm{k}_{\text {eff }}$ calculations. However, only trace quantities of ${ }^{12} \mathrm{C}$ were calculated $\left(1.6 \times 10^{-14}-2.2 \times 10^{-16}\right.$ at/b-cm), the change in concentrations of these isotopes from one cycle to the next is very small, and they are stable during the decay period, so their effect on reactivity with respect to the reference case is negligible. The PARAMETER card in the CSAS5 input was similar to that in the TRITON input, but a total of 51.5 histories were used: 10,000 histories per generation, 5,150 generations, and 150 skipped generations. 


\section{BERYLLIUM IRRADIATION POISONING AND REACTIVITY CALCULATIONS}

In order to develop a new methodology to predict the negative reactivity attributed by ${ }^{3} \mathrm{He},{ }^{6} \mathrm{Li}$, and other poisons in the beryllium reflector at startup, the model described in Section 2 of this report was employed along with typical cycle history data. HFIR currently operates at a power of $85 \mathrm{MW}$ for an average of about 25 days, and thus a total exposure of about $2125 \mathrm{MWd}$. The capacity factor at HFIR is approximately $50 \%$ and therefore the average down time $\left(t_{d}\right)$ between cycles is approximately 25 days.

\subsection{BUILDUP OF POISONS IN REFLECTOR}

Twenty typical HFIR cycles ( 25 days of irradiation +25 days of $t_{d}$ between cycles) were simulated and the beryllium reflector regions were depleted by flux using the TRITON control module in the SCALE package. The beginning composition of the beryllium reflector regions was $100 \%{ }^{9} \mathrm{Be}$. Reaching an equilibrium ${ }^{6} \mathrm{Li}$ concentration required approximately 5 cycles (Fig. 15). In these studies, twenty cycles were run to allow ${ }^{3} \mathrm{He}$ to buildup. The selection of twenty was arbitrary but the results of the calculations, shown in Fig. 15, reveal that at that point, the ${ }^{3}$ He inventory reasonably approaches equilibrium. Note that the goal of these studies is to revise a procedure for estimating the reactivity impact of ${ }^{3} \mathrm{He}$ and the most accurate determination of ${ }^{3} \mathrm{He}$ reactivity worth would always be obtained by modeling the equilibrium conditions.

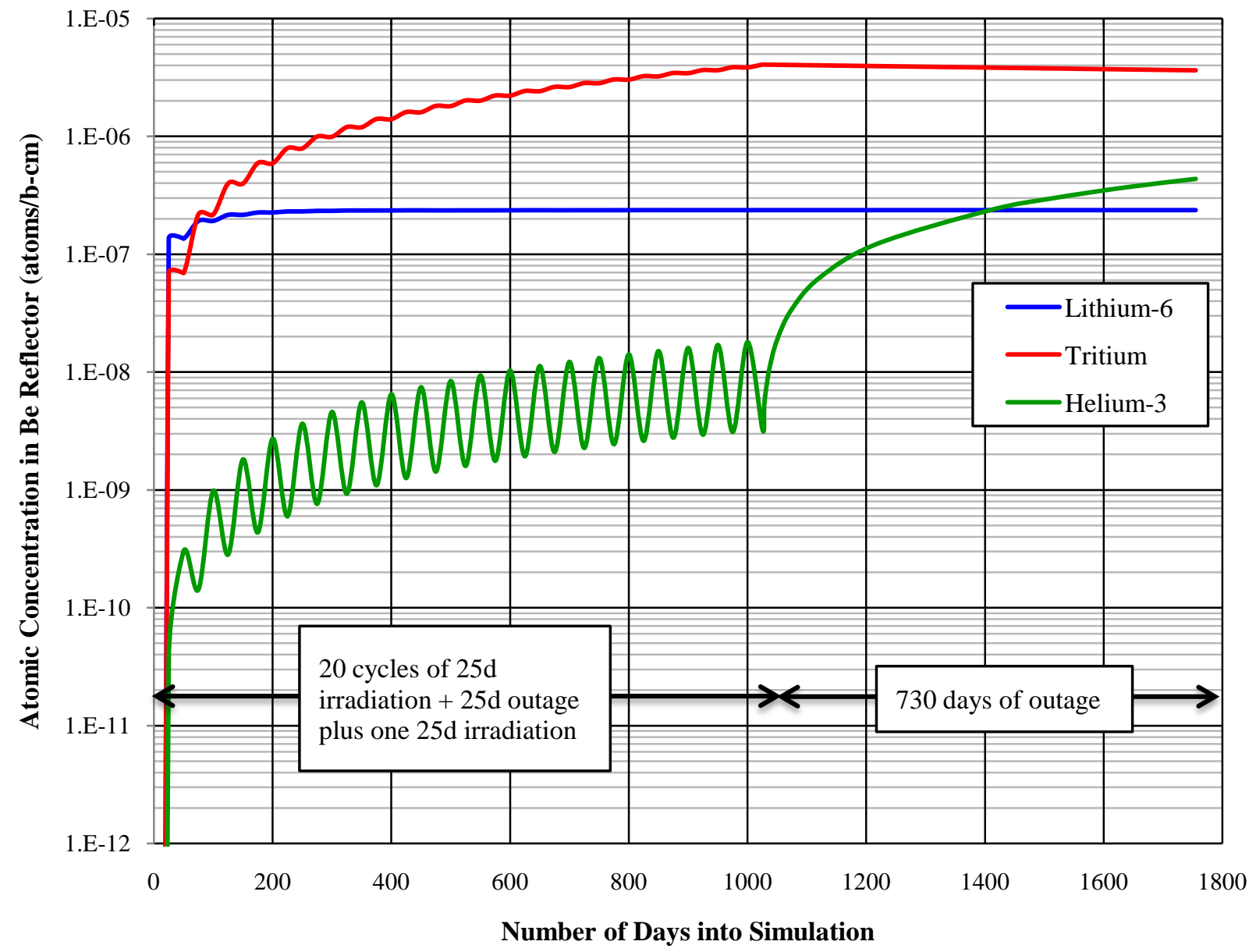

Fig. 15. ${ }^{6} \mathrm{Li},{ }^{3} \mathrm{H}$, and ${ }^{3} \mathrm{He}$ atomic concentration in reflector as a function of simulation time. 


\subsection{REACTIVITY CALCULATIONS}

In the SCALE/TRITON model, the fuel was not depleted under irradiation and 25 day burn-up step sizes (using the "bootstrap" calculation method) were used in association with the irradiation steps to minimize computing time and because the goal of these studies was to create the spatiallydependent ${ }^{3} \mathrm{He}$ source term in the reflector not follow behavior in the reactor core. The important parameters necessary to accurately model the transmutation of the nuclides in the beryllium reflector are the core leakage spectra and flux magnitude. It would be inefficient to simulate control element withdrawal and time and position dependent burn-up in the fuel when the leakage terms are the only data of interest and would require that the fuel and reflector regions be modeled with multiple axial zones. In order to determine whether or not the SCALE model produced an adequate core leakage spectrum with correct magnitude, the flux distribution as calculated in SCALE was compared to the time averaged flux distribution calculated in MCNP. This study is documented in Appendix A.

Following the end of the $t_{d}$ after the $20^{\text {th }}$ cycle, the 11 beryllium region compositions were extracted and inserted into a CSAS5 model in order to calculate a reference $\mathrm{k}_{\text {eff }}$, which was the BOC $21 \mathrm{k}_{\text {eff }}$. CSAS5 was used to increase the number of histories per transport calculation to 51.5 million histories to yield better statistics. Materials and geometry in the CSAS5 model are exactly the same as those in the TRITON model (except for updating the beryllium reflector compositions). The TRITON model used to deplete the reflector was converted into the CSAS5 model by removing all TRITON specific inputs, inserting CSAS5 specific inputs, and updating the reflector region compositions. For the CSAS5 calculations, the ${ }^{10} \mathrm{~B}$, which was being used to control reactivity, was removed from the CE channel and the corresponding $k_{\text {eff }}$ values were calculated. The ${ }^{10} \mathrm{~B}$ was removed from the $\mathrm{CE}$ channel so there were no poisons that would affect the reactivity of the core that is not normally there during operation.

In order to calculate the reactivity effect of ${ }^{3} \mathrm{He}$ as a function of $t_{d}$, multiple decay steps were analyzed. An additional 25 day irradiation period (cycle 21) was inserted into the original 20 cycle input case. Cases were run with decay steps of 3, 6, 12, 24, 48, 96, 192, 384, 492, 611, and 730 days following the last irradiation period. The OPUS functional module was used to output the reflector compositions (at/b-cm) for all the beryllium reflector materials at all of the time steps as generated by the ORIGEN code. The reflector compositions at the end of each decay step were then extracted from the OPUS plots and inserted into CSAS5 inputs and effective multiplication factors were calculated for the startup of a new cycle (BOC $22 \mathrm{k}_{\mathrm{eff}}$ ). The calculated $\mathrm{k}_{\mathrm{eff}}$ values for the reference case and the cases corresponding to the multiple decay steps are listed in Table 3.

The reference $\mathrm{k}_{\text {eff }}$, which corresponds to the BOC of the $21^{\text {st }}$ full power cycle, is $1.11415 \pm$ 0.00012. The cases $3,6, \ldots$, and 730 correspond to the BOC of the $22^{\text {nd }}$ full power cycle following shutdown periods of $3,6, \ldots$, and 730 days after the EOC 21 . Since the ${ }^{3} \mathrm{He}$ concentration increases as a function of time down, the effective multiplication factor decreases as a function of down time.

All of the $\mathrm{k}_{\text {eff }}$ values were inserted into a spreadsheet and the $\Delta \mathrm{k}_{\text {eff }} / \mathrm{k}_{\text {eff }}(\%)$ (reactivity effect of ${ }^{3} \mathrm{He}$ as a function of time) were calculated by subtracting the reference $\mathrm{k}_{\text {eff }}$ (BOC 21) from the BOC $22 \mathrm{k}_{\mathrm{eff}}$ values and then dividing by the product of the two:

$$
\text { reactivity }(\%)=\frac{\Delta k_{\text {eff }}}{k_{\text {eff }}}=\frac{k_{\text {eff }}^{\text {current }}-k_{\text {eff }}^{\text {reference }}}{k_{\text {eff }}^{\text {current }} \times k_{\text {eff }}^{\text {refence }}} \quad \text { Eq. } 11
$$

The $\Delta \mathrm{k}_{\text {eff }} / \mathrm{k}_{\text {eff }}$ values listed in Table 3 were converted into $\Delta \rho$ (\$) by dividing by 0.0076 , the delayed neutron fraction ( $\left.\beta_{\text {eff }}\right)$ associated with HFIR. ${ }^{11}$ The $\Delta \rho$ 's were then converted into $\Delta \mathrm{R}$ 's, which is used to show the change in symmetrical critical control element position associated with ${ }^{3} \mathrm{He}$ worth with respect to the reference case using the conversion factor 3.10 \$/in. That is, the control elements insert $\$ 3.10$ of negative reactivity for every inch that they are inserted (at the typical ASCCEP). The actual differential rod worth is dependent upon the control element position, but a 
value of 3.10 \$inch corresponds to "typical” startup positions (between 17.5 and 18 inches). The calculated $\Delta \rho$ and $\Delta \mathrm{R}$ values are plotted as a function of decay time in Fig. 16.

Table 3. Delta $\rho$ and delta $\mathrm{R}$ results.

\begin{tabular}{|c|c|c|c|c|c|c|c|c|}
\hline Case & $\mathbf{k}_{\text {eff }}$ & $\sigma_{\text {keff }}$ & $\Delta \mathbf{k}_{\text {eff }} / \mathbf{k}_{\text {eff }}(\%)$ & $\sigma_{\Delta \text { keff } / \text { keff }}(\%)$ & $\Delta \rho(\$)$ & $\sigma_{\rho}(\Phi)$ & $\Delta R$ (in) & $\sigma_{\Delta R}$ (in) \\
\hline reference & 1.11415 & 0.00012 & - & - & - & - & - & - \\
\hline 3 & 1.11578 & 0.00012 & 0.00131 & 0.00016 & 0.17252 & 2.12744 & 0.05565 & 0.00686 \\
\hline 6 & 1.11547 & 0.00012 & 0.00106 & 0.00016 & 0.13975 & 2.12757 & 0.04508 & 0.00686 \\
\hline 12 & 1.11499 & 0.00012 & 0.00068 & 0.00016 & 0.08897 & 2.12778 & 0.02870 & 0.00686 \\
\hline 24 & 1.11415 & 0.00012 & 0.00000 & 0.00016 & 0.00000 & 2.12815 & 0.00000 & 0.00686 \\
\hline 48 & 1.11226 & 0.00013 & -0.00153 & 0.00017 & -0.20068 & 2.21921 & -0.06473 & 0.00716 \\
\hline 96 & 1.10890 & 0.00012 & -0.00425 & 0.00016 & -0.55913 & 2.13048 & -0.18036 & 0.00687 \\
\hline 192 & 1.10286 & 0.00013 & -0.00919 & 0.00017 & -1.20897 & 2.22245 & -0.38999 & 0.00717 \\
\hline 384 & 1.09357 & 0.00012 & -0.01689 & 0.00016 & -2.22250 & 2.13782 & -0.71694 & 0.00690 \\
\hline 492 & 1.08948 & 0.00013 & -0.02032 & 0.00017 & -2.67419 & 2.22760 & -0.86264 & 0.00719 \\
\hline 611 & 1.08548 & 0.00012 & -0.02371 & 0.00016 & -3.11924 & 2.14203 & -1.00621 & 0.00691 \\
\hline 730 & 1.08169 & 0.00012 & -0.02693 & 0.00016 & -3.54396 & 2.14408 & -1.14321 & 0.00692 \\
\hline
\end{tabular}

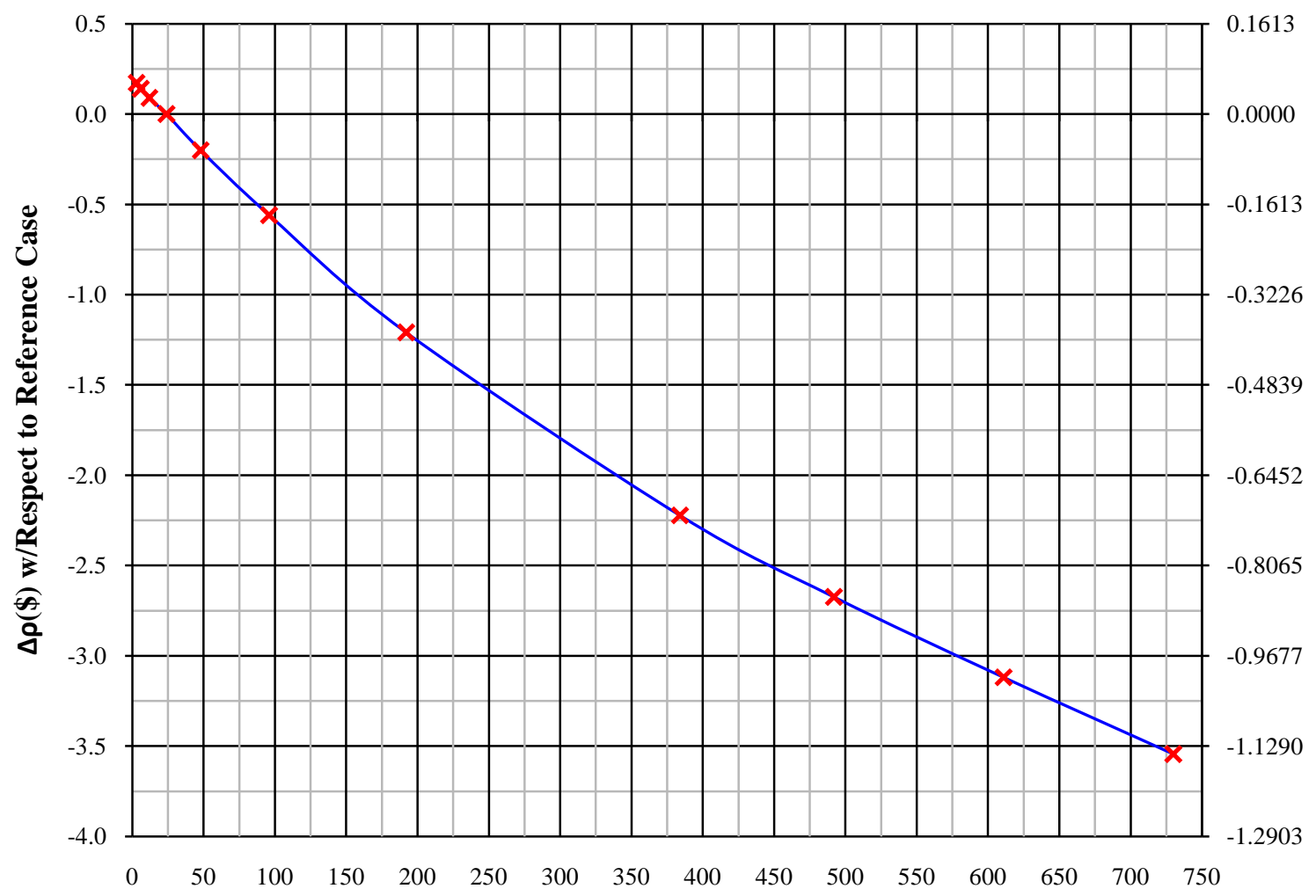

Outage Time (Days)

Fig. 16. ${ }^{3}$ He reactivity effects as a function of shutdown time with respect to reference case. 


\subsection{PROPOSED SHUTDOWN POISON ACCOUNTABILITY PROCEDURE}

The $\Delta \rho$ curve was then shifted such that the $\Delta \rho$ value at zero shutdown time is zero because the curve should reflect the "added" reactivity poisoning effect of ${ }^{3} \mathrm{He}$ that builds in following shutdown (i.e. it is simply a normalization factor). Thus, the value of reactivity at a shutdown of zero was subtracted from all the points on the curve. The curve based on a zero $\Delta \rho$ value at zero shutdown time is compared to the curve used in the current ESCCEP calculation in Fig. 17. Again, in Fig. 17, the typical differential rod worth of 3.10 \$/in was used. For short outages, the current and proposed methodologies yield similar poisoning effects, but for long outages, the differences are significant. Best fit equations were developed for the curve in Fig. 17 that corresponds to the proposed methodology and are listed in Appendix B.

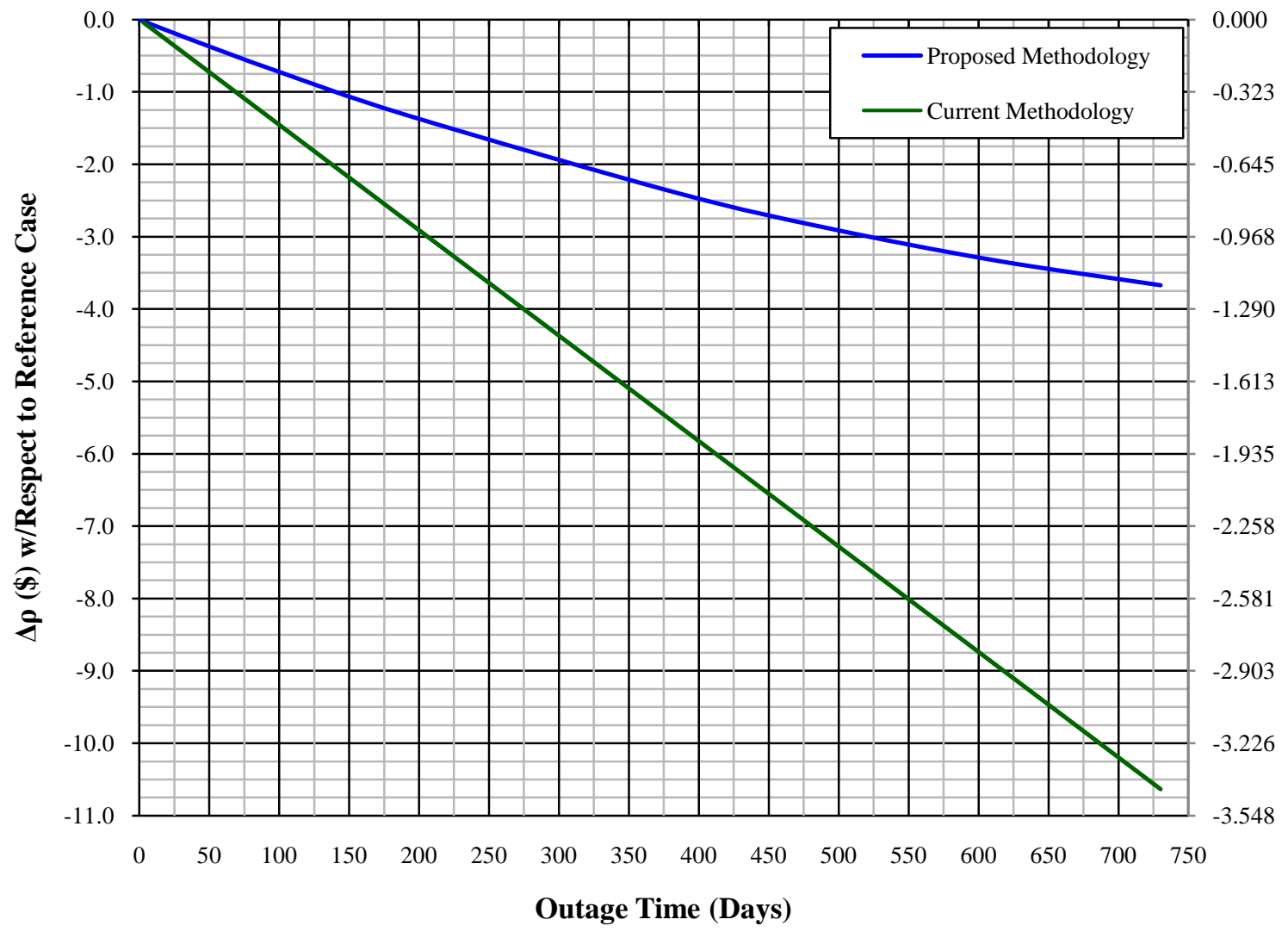

Fig. 17. Comparison of current RRD procedure and newly derived ${ }^{3} \mathrm{He}$ poison estimates.

The proposed methodology for Section 6.8 of the ESCCEP calculation to calculate the $\Delta R$ associated with shutdown ${ }^{3} \mathrm{He}$ poisoning of the reflector is listed below. The methodology described below uses the $2^{\text {nd }}$ order curve fit equation. The current cycle is the cycle in which the ESCCEP is being calculated and the reference cycle is a typical cycle (usually the previous cycle). 
a.

Current Cycle

The reflector is new at start of cycle $\Delta \rho=0.0$

The reflector has one or more cycles of irradiation.

$\mathrm{Td}_{\mathrm{c}}=\mathrm{t}_{\underline{c}}$ days (the decay time on the reflector)

$\Delta \rho_{\mathrm{c}}=-\left(3.47692 \times 10^{-6}\right) \mathrm{t}_{\mathrm{c}}{ }^{2}+\left(7.56879 \times 10^{-3}\right) \mathrm{t}_{\mathrm{c}}$

c. Reference Cycle

The reflector is new at start of cycle $\Delta \rho=0.0$

The reflector has one or more cycles of irradiation.

$\mathrm{Td}_{\mathrm{r}}=\underline{\mathrm{t}}_{\underline{r}}$ days (the decay time on the reflector)

$\Delta \rho_{r}=-\left(3.47692 \times 10^{-6}\right) t_{r}^{2}+\left(7.56879 \times 10^{-3}\right) t_{r}$

c. $\Delta \rho$ Current Cycle

$\underline{\Delta \rho_{\mathrm{C}}}$ dollars (6.8a)

$\Delta \rho$ Reference Cycle

$\Delta \rho_{\underline{r}}$ dollars (6.8b)

$\Delta \rho 8=(6.8 \mathrm{a})-(6.8 \mathrm{~b})=$

$\underline{\Delta \rho}$ dollars

d. $\quad$ DRW $=$ Differential Rod Worth at ESCCEP dollars/inch

$$
\Delta \mathrm{R} 8=\Delta \rho 8 /(\mathrm{DRW})=\underline{\Delta \mathrm{R}} \text { inches }
$$

In the above procedure $T d_{c}$ and $T d_{r}$ denote the current and reference time down in days, respectively while $\Delta \rho_{\mathrm{c}}$ and $\Delta \rho_{\mathrm{r}}$ denote the current and reference change in reactivity in dollars, respectively. The symbols $\Delta \rho 8$ and $\Delta \mathrm{R} 8$ represent the change in reactivity and the change in symmetrical critical control element positions between the current and reference cycles, respectively. The 8 signifies that the reactivity effects were derived from step 6.8 of the ESCCEP calculation. The reactivity difference in dollars must first be calculated and then the user of the procedure must input the differential rod worth (DRW) at startup in dollars per inch before calculating the change in symmetrical critical control element position for the current cycle. A table containing the DRW as a function of ESCCEP is located in 7.3 of the ESCCEP calculation and Appendix B of this report.

This is the way it should be done in the whole procedure but because startup position is almost always the same number, the original authors "plugged in” 3.10 dollars per inch. In reality, the whole ESCCEP procedure has to be done iteratively by choosing the rod worth value (\$3.10/inch), calculate the startup position, check the chart to determine control rod worth at that position, if different from $\$ 3.10 /$ inch, use the new value and recalculate the startup position. This procedure should be repeated until the values converge.

\subsection{VALIDATION OF PROPOSED METHODOLOGY AGAINST ASCCEP DATA}

The correlation was validated with ASCCEP measurements from 39 varying cycles. The ESCCEP calculations from cycles 383-421(with the exception of cycles 385-387, 390b, 393b, and 396B) (References 7-8 and 12-45) were utilized. A spreadsheet that is maintained by R. T. Primm, III that contains ESCCEP and ASCCEP data since cycle 383 was used. The $\triangle \mathrm{R}$ values associated with the ${ }^{3} \mathrm{He}$ worth were updated with the new correlation and then the new ESCCEP values were compared to the ASCCEP values.

Data from the ESCCEP calculations for cycles 383 - 421 were utilized to compare the current 
and proposed methodologies in determining the poisoning effect of ${ }^{3} \mathrm{He}$ in the beryllium reflector on the symmetrical critical control element position. For this study it was assumed that uncertainty only exists in the ${ }^{3} \mathrm{He}$ poison effect, i.e. the reactivity effects associated with the fuel worth, cylinder and plate burn-up, cylinder and plate ${ }^{182}$ Ta worths, etc remained unchanged from the original ESCCEP calculations. The ESCCEP calculated with both the current methodology and the proposed methodology were compared to the ASCCEPs and the difference in the actual and estimated symmetrical critical control element positions are shown in Fig. 18.

On average, the proposed methodology better estimates the symmetrical critical control element positions. The average absolute difference between actual and estimated positions for the current and proposed methodologies for the 39 cycles is 0.174 inches and 0.154 inches, respectively. The proposed methodology better predicts the ${ }^{3} \mathrm{He}$ effect for longer down times, but little difference is observed for shorter down times. The bold bars in Fig. 18 that extend at a delta of 0.5 inches were included because a difference between the ASCCEP and ESCCEP of $\sim 0.5$ inches is the difference that will cause the reactor to be shutdown and a technical evaluation to be performed to resolve the discrepancy prior to startup. The difference of -0.56 inches calculated for cycle 408 using the current methodology was the motivation of this study. Note that for cycle $383\left(t_{d}=430\right.$ days) the methodology explained in Section 1.4 was used, which produced an ASCCEP - ESCCEP value of 0.180 inch. However, if the current methodology would have been utilized instead, an ASCCEP ESCCEP value of -0.858 inches would have been obtained (denoted with a star on Fig. 18). Thus, the current methodology over predicts the reactivity effects attributed to shutdown ${ }^{3} \mathrm{He}$.

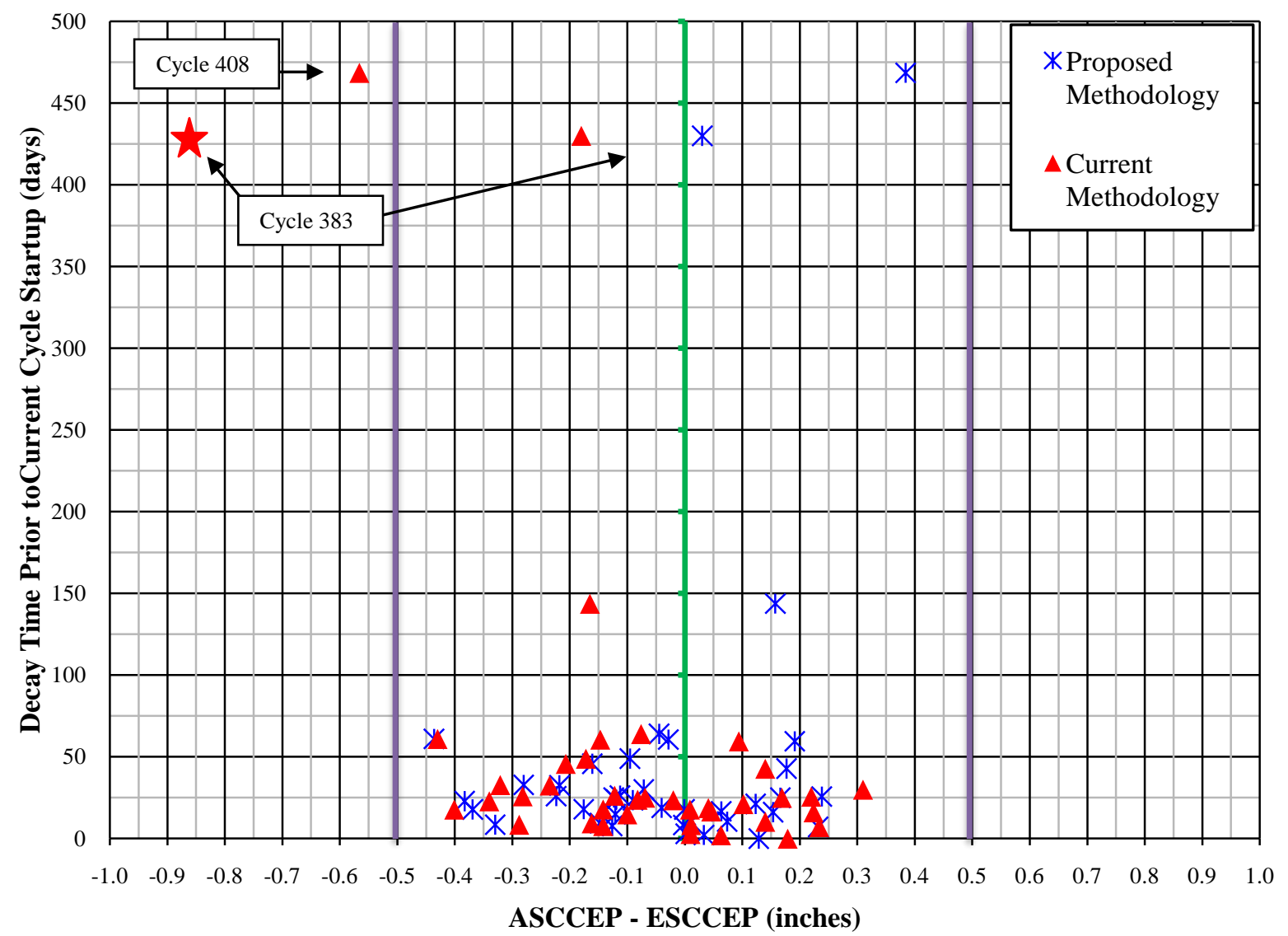

Fig. 18. Comparison of current and proposed ESCCEP methodologies against ASCCEP data. 
The statistical program $\mathrm{R}$ was used to summarize the results shown in Fig. 18. The outage time prior to the current and reference cycles and the ASCCEP - ESCCEP values for both the current and proposed methodologies were analyzed. The statistical results are shown in Table 4 and a box plot comparing the current and proposed methodologies is illustrated in Fig. 19. Note that the minimum outage time is 0.0 days which shows when the beryllium reflector is changed out. The spread for the proposed methodology is slightly less than the current methodology and both the median and mean of the 39 cycles for the proposed methodology is closer to zero than for the current methodology.

Table 4. Statistical results for current and proposed methodologies.

\begin{tabular}{c|c|c|c|c}
\hline Statistic & $\begin{array}{c}\text { Current } \mathbf{T}_{\mathbf{d}} \\
\text { (days) }\end{array}$ & $\begin{array}{c}\text { Reference } \mathbf{T}_{\mathbf{d}} \\
\text { (days) }\end{array}$ & $\begin{array}{c}\text { Current A-E } \\
\text { (inches) }\end{array}$ & $\begin{array}{c}\text { Proposed A-E } \\
\text { (inches) }\end{array}$ \\
\hline Minimum & 0.0000 & 0.0000 & -0.5660 & -0.4360 \\
\hline $1^{\text {st }}$ Quartile & 15.2100 & 9.2720 & -0.1780 & -0.1425 \\
\hline Median & 23.6700 & 22.9700 & -0.0790 & -0.0425 \\
\hline Mean & 50.4300 & 50.8620 & -0.0699 & -0.0408 \\
\hline $3^{\text {rd }}$ Quartile & 40.3100 & 47.3730 & 0.0863 & 0.1109 \\
\hline Maximum & 468.5200 & 485.0300 & 0.3100 & 0.3840 \\
\hline Range & 468.5200 & 485.0300 & 0.8760 & 0.8200 \\
\hline
\end{tabular}

Fig. 19. Box plot for current and proposed methodologies. 
This page blank 


\section{CONCLUSIONS}

A new methodology for predicting the reactivity impact of ${ }^{3} \mathrm{He},{ }^{6} \mathrm{Li}$, and other poisons in the beryllium reflector of HFIR was developed to amend the ORNL Research Reactor Division's Estimated Symmetrical Critical Control Element Position (ESCCEP) calculation procedure. A new procedure is needed to better estimate the critical control element position following a long outage because the current procedure has proven to be inaccurate following long outages.

When ${ }^{9} \mathrm{Be}$ is irradiated by fast neutrons (energies above $\sim 1 \mathrm{MeV}$ ), it undergoes $(\mathrm{n}, \alpha)$ reactions that lead to a buildup of the ${ }^{3} \mathrm{He}$ and ${ }^{6} \mathrm{Li}$ isotopes. Both of these isotopes have large neutron absorption cross sections in the thermal energy range and thus the negative reactivity impact due to these poisons must be correctly accounted for at reactor startup when predicting the symmetrical critical control element position.

Through calculations, it was shown that ${ }^{6} \mathrm{Li}$ reached an equilibrium concentration after approximately 5 cycles, which when averaged over the entire volume of the beryllium reflector amounts to about $2.36 \times 10^{-07}$ atoms/barn-centimeter. Unlike ${ }^{6} \mathrm{Li},{ }^{3} \mathrm{He}$ didn't reach an equilibrium concentration. The amount of ${ }^{3} \mathrm{He}$ in the reflector decreased during irradiation primarily due to the ${ }^{3} \mathrm{He}(\mathrm{n}, \mathrm{p})$ reaction, which produces tritium. During outages the amount of ${ }^{3} \mathrm{He}$ significantly increased due to the decay of tritium, which is produced by the ${ }^{6} \mathrm{Li}(\mathrm{n}, \alpha)$ and ${ }^{3} \mathrm{He}(\mathrm{n}, \mathrm{p})$ reactions.

The methodology developed in this study (a new proposed methodology) was compared to the methodology that is currently employed, and on average the proposed methodology better estimates the symmetrical critical control element positions, especially for long outages which allow for large amounts of ${ }^{3} \mathrm{He}$ to buildup in the reflector. Utilizing the correlation between the beryllium poison and change in symmetrical control element position developed in this report, an average absolute difference between actual and estimated positions of 0.154 inches (assuming all other reactivity effects were correctly calculated) was observed after reevaluating the ESCCEP calculations for 39 startups between HFIR cycles 383 - 421.

The explanation for the observed inadequacy of the current procedure for predicting the poisoning effect following long (several months) shutdowns was due to less than linear buildup of ${ }^{3} \mathrm{He}$ in the reflector as a function of shutdown time. The current procedure for estimating poisoning effect had assumed a linear relationship. 
This page blank 


\section{REFERENCES}

1. T. A. Tomberlin, Beryllium - A Unique Material in Nuclear Applications, Idaho National Engineering and Environmental Laboratory, Idaho Falls, ID.

2. K. J. Andrzejewski and T. A. Kulikowska, Isotopic Transmutations in Irradiated Beryllium and Their Implications on Maria Reactor Operation, Institute of Atomic Energy, Poland, Nuclear Technology, Vol. 146, April 2004.

3. S. Kalcheva, E. Koonen, and B. Ponsard, Validation of MCNP \& ORIGEN-S 3-D Computational Model for Reactivity Predictions During BR2 Operation, BR2 Division, SCKCEN, Belgium.

4. R. A. Dragoset, et. al., Periodic Table Atomic Properties of the Elements, National Institute of Standards and Technology.

5. "Cross Section Plotter." Table of Nuclides. Korea Atomic Energy Research Institute. $<$ http://atom.kaeri.re.kr/>.

6. R. D. Cheverton and T. M. Sims, HFIR Core Nuclear Design, ORNL-4621, Oak Ridge National Laboratory, July 1971.

7. R. T. Primm, III, Estimated Symmetrical Critical Control Element Position (ESCCEP) for Cycle 408, C-HFIR-2007-035, May 2007.

8. R. B. Rothrock, Estimated Symmetrical Critical Control Element Position (ESCCEP) for Cycle 383, C-HFIR-2001-030, December 2001.

9. SCALE: A Modular Code system for Performing Standardized Computer Analyses for Licensing Evaluations, ORNL/TM-2005/39, Version 6.1, Vols. I-III, Oak Ridge National Laboratory. January 2009.

10. R. T. Primm, III and N. Xoubi, Modeling of the High Flux Isotope Reactor Cycle 400, ORNL/TM-2004/251, Oak Ridge National Laboratory, August 2005.

11. C. Galvez Velit, R. T. Primm, III, and J. C. Gehin, Partial Safety Analysis for a Reduced Uranium Enrichment Core for the High Flux Isotope Reactor, ORNL/TM-2007/226, April 2009.

12. R. B. Rothrock, Estimated Symmetrical Critical Control Element Position (ESCCEP) for Cycle 384, C-HFIR-2002-008, March 2002.

13. R. T. Primm, III, Estimated Symmetrical Critical Control Element Position (ESCCEP) for Cycle 388, C-HFIR-2002-023, July 2002.

14. R. T. Primm, III, Estimated Symmetrical Critical Control Element Position (ESCCEP) for Cycle 389, C-HFIR-2002-026, August 2002.

15. R. T. Primm, III, Estimated Symmetrical Critical Control Element Position (ESCCEP) for Cycle 390, C-HFIR-2002-031, October 2002.

16. R. T. Primm, III, Estimated Symmetrical Critical Control Element Position (ESCCEP) for Cycle 391, C-HFIR-2002-036, November 2002.

17. R. T. Primm, III, Estimated Symmetrical Critical Control Element Position (ESCCEP) for Cycle 392, C-HFIR-2002-040, December 2002.

18. R. T. Primm, III, Estimated Symmetrical Critical Control Element Position (ESCCEP) for Cycle 393, C-HFIR-2003-006, January 2003.

19. R. T. Primm, III, Estimated Symmetrical Critical Control Element Position (ESCCEP) for Cycle 394, C-HFIR-2003-014, May 2003.

20. R. T. Primm, III, Estimated Symmetrical Critical Control Element Position (ESCCEP) for Cycle 395, C-HFIR-2003-019, June 2003.

21. R. T. Primm, III, Estimated Symmetrical Critical Control Element Position (ESCCEP) for Cycle 396, C-HFIR-2003-025, August 2003.

22. R. T. Primm, III, Estimated Symmetrical Critical Control Element Position (ESCCEP) for Cycle 397, C-HFIR-2003-034, September 2003.

23. R. T. Primm, III, Estimated Symmetrical Critical Control Element Position (ESCCEP) for 
Cycle 398, C-HFIR-2003-041, December 2003.

24. R. T. Primm, III, Estimated Symmetrical Critical Control Element Position (ESCCEP) for Cycle 399, C-HFIR-2004-002, January 2004.

25. R. T. Primm, III, Estimated Symmetrical Critical Control Element Position (ESCCEP) for Cycle 400, C-HFIR-2004-019, April 2004.

26. R. T. Primm, III, Estimated Symmetrical Critical Control Element Position (ESCCEP) for Cycle 401, C-HFIR-2004-040, June 2004.

27. R. T. Primm, III, Estimated Symmetrical Critical Control Element Position (ESCCEP) for Cycle 402, C-HFIR-2004-058, August 2004.

28. R. T. Primm, III, Estimated Symmetrical Critical Control Element Position (ESCCEP) for Cycle 403, C-HFIR-2005-105, January 2005.

29. R. T. Primm, III, Estimated Symmetrical Critical Control Element Position (ESCCEP) for Cycle 404, C-HFIR-2005-135, March 2005.

30. R. T. Primm, III, Estimated Symmetrical Critical Control Element Position (ESCCEP) for Cycle 405, C-HFIR-2005-153, May 2005.

31. R. T. Primm, III, Estimated Symmetrical Critical Control Element Position (ESCCEP) for Cycle 406, C-HFIR-2005-166, June 2005.

32. R. T. Primm, III, Estimated Symmetrical Critical Control Element Position (ESCCEP) for Cycle 407, C-HFIR-2005-220, December 2005.

33. R. T. Primm, III, Estimated Symmetrical Critical Control Element Position (ESCCEP) for Cycle 409, C-HFIR-2007-045, June 2007.

34. R. T. Primm, III, Estimated Symmetrical Critical Control Element Position (ESCCEP) for Cycle 410, C-HFIR-2007-047, August 2007.

35. R. T. Primm, III, Estimated Symmetrical Critical Control Element Position (ESCCEP) for Cycle 411, C-HFIR-2007-060, November 2007.

36. R. T. Primm, III, Estimated Symmetrical Critical Control Element Position (ESCCEP) for Cycle 412, C-HFIR-2007-064, December 2007.

37. R. T. Primm, III, Estimated Symmetrical Critical Control Element Position (ESCCEP) for Cycle 413, C-HFIR-2008-003, February 2008.

38. R. T. Primm, III, Estimated Symmetrical Critical Control Element Position (ESCCEP) for Cycle 414, C-HFIR-2008-012, March 2008.

39. R. T. Primm, III, Estimated Symmetrical Critical Control Element Position (ESCCEP) for Cycle 415, C-HFIR-2008-021, May 2008.

40. R. T. Primm, III, Estimated Symmetrical Critical Control Element Position (ESCCEP) for Cycle 416, C-HFIR-2008-029, July 2008.

41. R. T. Primm, III, Estimated Symmetrical Critical Control Element Position (ESCCEP) for Cycle 417, C-HFIR-2008-035, September 2008.

42. R. T. Primm, III, Estimated Symmetrical Critical Control Element Position (ESCCEP) for Cycle 418, C-HFIR-2008-048, November 2008.

43. R. T. Primm, III, Estimated Symmetrical Critical Control Element Position (ESCCEP) for Cycle 419, C-HFIR-2008-055, December 2008.

44. R. T. Primm, III, Estimated Symmetrical Critical Control Element Position (ESCCEP) for Cycle 420, C-HFIR-2009-006, February 2009.

45. R. T. Primm, III, Estimated Symmetrical Critical Control Element Position (ESCCEP) for Cycle 421, C-HFIR-2009-018, May 2009.

46. R. T. Primm, III, et. al., Design Study for a Low Enriched Uranium Core for the High Flux Isotope Reactor, ORNL/TM-2009/87, Oak Ridge National Laboratory, March 2009. 
This page blank. 


\section{APPENDIX A}

\section{BENCHMARKING OF SCALE MODEL}

The SCALE model was benchmarked against the cycle 400 model by performing $\mathrm{k}_{\text {eff }}$ and flux distribution comparisons. The effective multiplication factors were calculated at BOC conditions and the control elements in the MCNP model were modeled as fully withdrawn since the SCALE model developed for this study doesn't exclusively model the control elements. No poisons were therefore modeled in the control element channel in the SCALE model. The calculated $\mathrm{k}_{\mathrm{eff}}$ values for both the MCNP and SCALE models are listed in Table A1. The delta $k_{\text {eff }}$ between the two models is $40 \pm 2$ cents, which is likely caused by a less complex geometry utilized in the SCALE model, continuous energy cross section representation in MCNP versus group energy cross sections in KENO, potential differences in the sources of the nuclear data (versions of ENDF), and perhaps other factors.

Table A1. Multiplication factor comparison for MCNP and SCALE models.

\begin{tabular}{c|c|c}
\hline Case & $\mathbf{k}_{\text {eff }}$ & $\boldsymbol{\sigma}_{\text {keff }}$ \\
\hline MCNP & 1.11974 & 0.00012 \\
\hline SCALE & 1.12281 & 0.00012 \\
\hline
\end{tabular}

In order to justify using large burn-up step sizes (12.5 days), the thermal and total fluxes utilized in the SCALE model were compared to the time averaged thermal and total fluxes as calculated in MCNP. Reference 46 documents a Monte Carlo depletion study for HFIR cycle 400. ALEPH, a Monte Carlo based depletion tool developed at SCK-CEN in Belgium, was used to deplete the HFIR fuel elements as a function of time while simulating the control element withdrawal. The IFE and OFE were divided into 8 and 9 radial regions, respectively, and both of the fuel elements were divided into 19 regions along the axial direction. The cycle 400 core was irradiated for 24 days and 8 hours, which was simulated using 24 depletion steps of 1 day length intervals followed by a depletion step of 8 hours. Ten of the MCNP inputs that were created by the ALEPH code were utilized to calculate the time averaged thermal and total fluxes.

The energy card (e4) derived from the ALEPH input was deleted from each MCNP input and cell flux tallies (f4) were inserted for each of the 11 reflector regions. The thermal energy bin ranged from $0 \mathrm{eV}$ to $3 \mathrm{eV}$ and the non-thermal bin ranged from $3 \mathrm{eV}$ to $20 \mathrm{MeV}$. These energies were chosen based on the SCALE 238 group ENDF/V-II library energy bins since this data library was used for this study. The ten inputs used to calculate the time averaged data corresponds to the BOC and the $1^{\text {st }}, 5^{\text {th }}, 10^{\text {th }}, 14^{\text {th }}, 17^{\text {th }}, 19^{\text {th }}, 21^{\text {st }}, 23^{\text {rd }}$, and $24^{\text {th }}$ day into irradiation. These inputs were chosen based on the control element withdrawal curve used for the depletion study. Longer step sizes were chosen during the middle-of-cycle (MOC) when the control elements positions change slowly and shorter step sizes were chosen at the BOC and EOC when the control elements are withdrawn more rapidly. A plot of the simulated control element withdrawal as a function of irradiation time for cycle 400 and the discretization of the steps used to determine the time averaged thermal and total neutron fluxes in the beryllium reflector are shown in Fig. A1. 


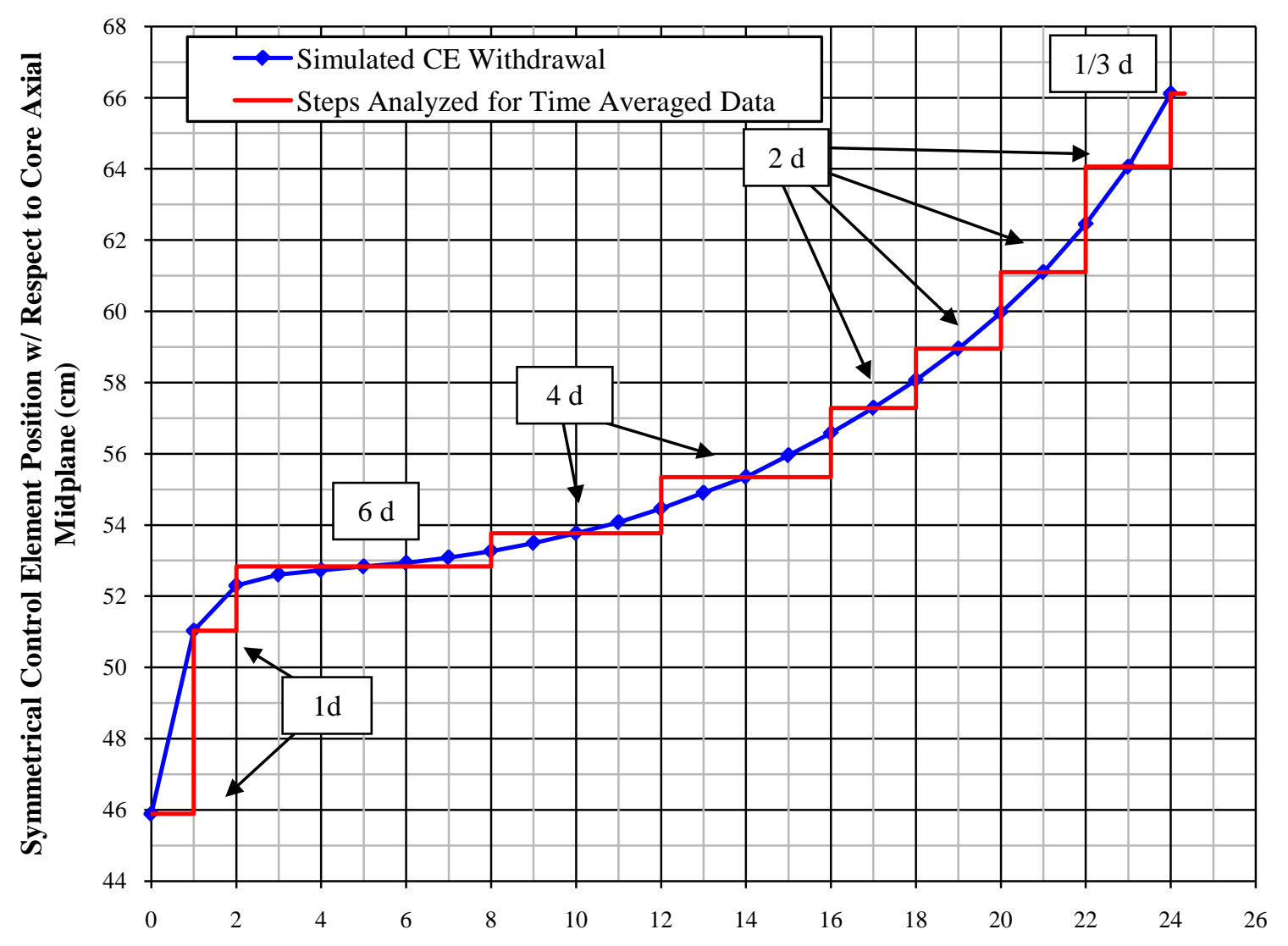

Days into Irradiation

Fig. A1. Cycle 400 simulated control element withdrawal curve and discretization of steps used to calculate time averaged data.

The thermal and total track length estimates of flux $\left(1 / \mathrm{cm}^{2}\right)$ were extracted from each of the 10 outputs for each of the 11 reflector regions and the time averaged track length estimates of flux were calculated. The track length estimates of flux were converted into neutron fluxes by multiplying by the total source strength, $\mathrm{S}$, of $6.44 \times 10^{18}$ neutrons/second. The total source strength was calculated as follows:

$$
\mathrm{S}=\frac{\mathrm{P} \bar{v}}{\mathrm{eQk}_{\mathrm{eff}}}=\frac{\left(85 \times 10^{6} \mathrm{~W}\right) \times\left(2.439 \frac{\text { neutrons }}{\text { fission }}\right)}{\left(1.602177 \times 10^{-13} \frac{\mathrm{J}}{\mathrm{Mev}}\right) \times\left(200.7 \frac{\mathrm{MeV}}{\text { fission }}\right) \times(1.00)}=6.44 \times 10^{18} \text { neutrons } / \text { second }
$$

The thermal and total fluxes utilized in the SCALE calculations used for this study and the time averaged thermal and total fluxes as calculated in MCNP (derived from ALEPH) for the beryllium reflector regions are shown in Fig. A2. The small bumps in the MCNP flux profile that peak at about $41 \mathrm{~cm}$ from the core centerline are caused by the vertical experiment facilities (VXFs) in the permanent beryllium reflector (11 small VXFs, 5 small VXFs, and 6 large VXFs are located concentric with the core on a circle of radius $39.2 \mathrm{~cm}, 44.1 \mathrm{~cm}$, and $46.3 \mathrm{~cm}$, respectively), explicitly modeled in MCNP but homogenized with Be in the SCALE model. 


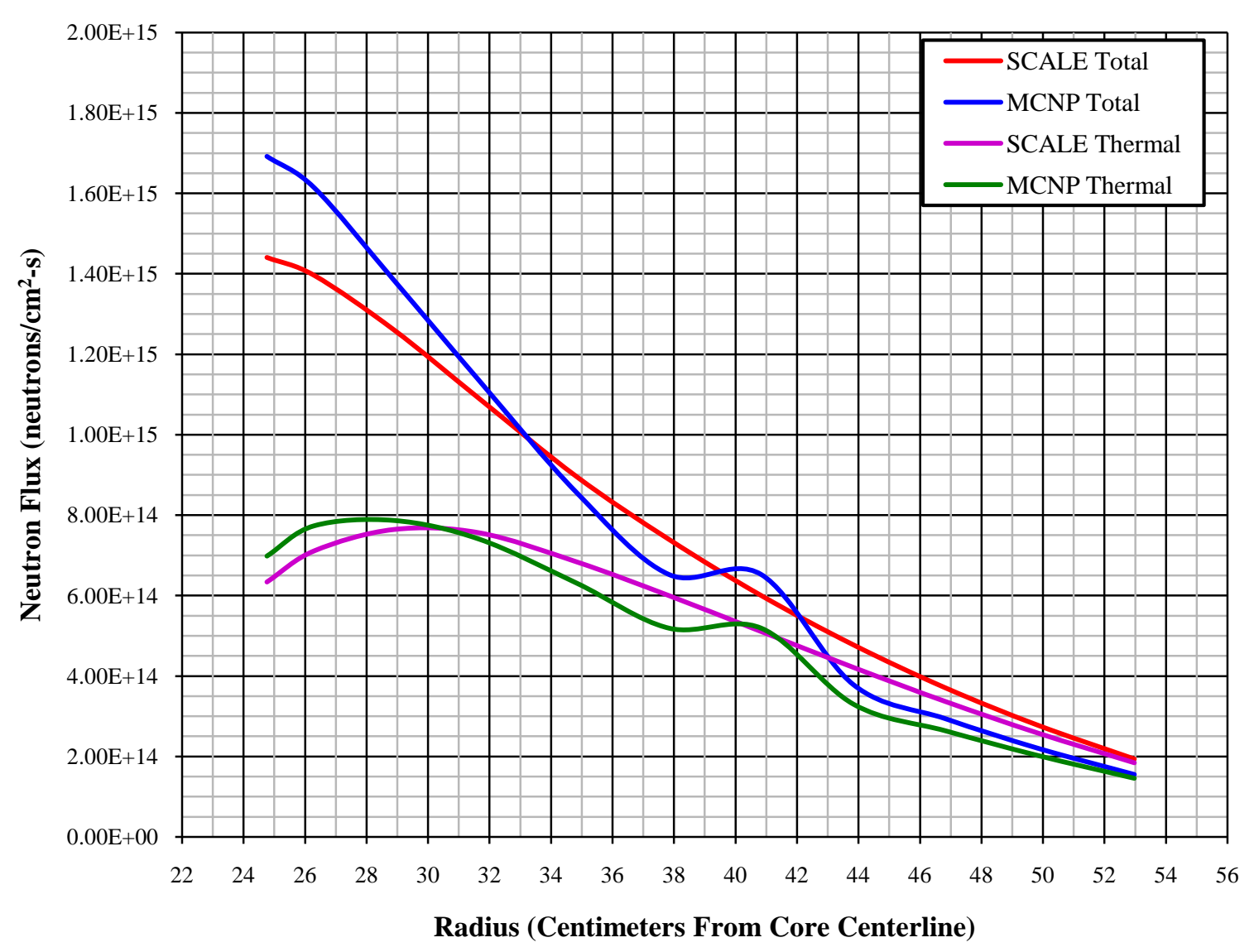

Fig. A2. Comparison of time averaged fluxes calculated in MCNP and fluxes used in SCALE. 


\section{APPENDIX B \\ BEST FIT EQUATIONS AND COMPARISONS}

After plotting the $\Delta \rho$ values as a function of shutdown time, best fit equations relating $\Delta \rho$ to shutdown time were generated. The first, second, and third order equations are shown below where the variable $\mathrm{t}$ is the outage time in days. After $\Delta \rho$ is calculated, $\Delta \mathrm{R}$ can be computed by dividing $\Delta \rho$ by the differential rod worth. The rod worth varies as a function of position and therefore the symmetrical position must first be estimated and then the differential rod worth can be interpolated from the values in Table B1.

To calculate $\Delta \rho(\$)$ :

$\Delta \rho(\$)=-\left(5.27101 \times 10^{-3}\right) \mathrm{t}$

$\Delta \rho(\$)=\left(3.47692 \times 10^{-6}\right) \mathrm{t}^{2}-\left(7.56879 \times 10^{-3}\right) \mathrm{t}$

$\Delta \rho(\$)=-\left(3.53127 \times 10^{-9}\right) \mathrm{t}^{3}+\left(7.31400 \times 10^{-6}\right) \mathrm{t}^{2}-\left(8.57881 \times 10^{-3}\right) \mathrm{t}$

To calculate $\Delta \mathrm{R}$ (inches):

$$
\Delta \mathrm{R}(\mathrm{in})=\frac{\Delta \rho(\$)}{\text { Differential Rod Worth }(\$ / \text { inch })}
$$

Table B1. Differential worth of control elements at ESCCEP.

\begin{tabular}{c|c}
\hline ESCCEP (inches) & Differential Rod Worth (\$/inch) \\
\hline 16.5 & 2.48 \\
\hline 17.0 & 2.68 \\
\hline 17.5 & 3.10 \\
\hline 18.0 & 3.10 \\
\hline 19.0 & 2.76 \\
\hline 20.0 & 2.40 \\
\hline 22.0 & 1.50 \\
\hline 24.0 & 0.90 \\
\hline 26.0 & 0.40 \\
\hline
\end{tabular}

The use of the three equations were compared to each other by applying them to the ESCCEP for cycles 383 - 421 and then comparing the results to the ASCCEP data. The difference in ESCCEP and ASCCEP produced by the three equations are plotted against each other in Fig. B1. The average absolute differences between ASCCEP and ESCCEP generated using the $1^{\text {st }}, 2^{\text {nd }}$, and $3^{\text {rd }}$ degree correlations are $0.161,0.154$, and 0.157 inches, respectively. Thus, there are no significant benefits of using one over the other. The three correlations are compared to the actual calculated values in Table B1. The second order equation was chosen to be applied to the ESCCEP procedure because the linear correlation produces the largest percent differences when compared to the calculated results and no considerable advantages of using the third order equation over the second order equation are observed. The large percent differences listed in Table B2 for short outages are due to shifting the 
curves such that the $\Delta \rho$ values at zero shutdown time is zero and are insignificant since the $\Delta \rho$ 's corresponding to outages are small.

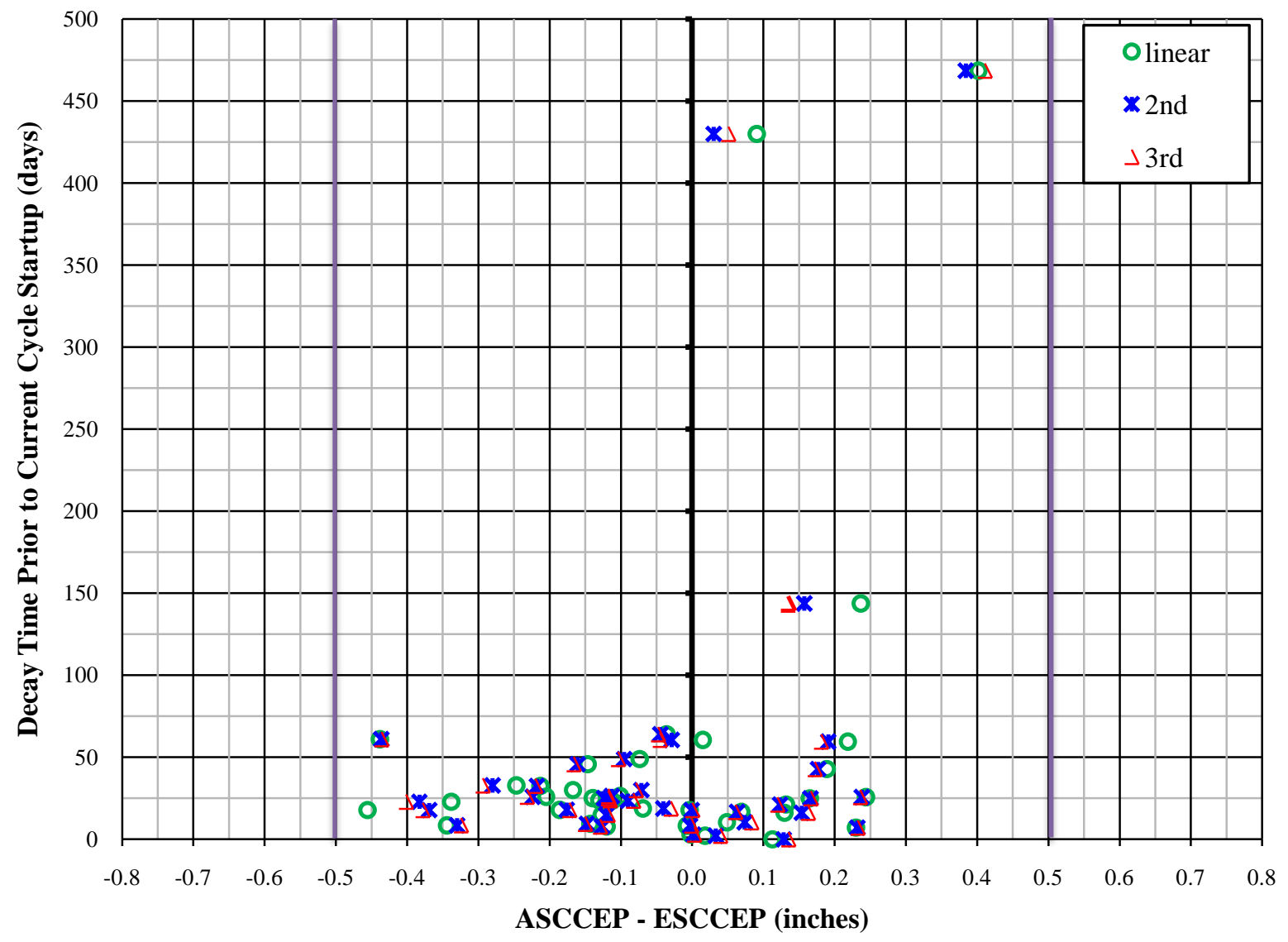

Fig. B1. Comparison of $1^{\text {st }}, 2^{\text {nd }}$, and $3^{\text {rd }}$ order best fit equations to ASCCEP data.

Table B2. Comparison of $\mathbf{1}^{\text {st }}$, $2^{\text {nd }}$, and $3^{\text {rd }}$ order best fit equations to calculated results.

\begin{tabular}{|c|c|c|c|c|c|c|c|}
\hline \multirow{2}{*}{ Case } & \multirow{2}{*}{$\begin{array}{c}\text { Calculated } \\
\Delta \rho(\$)\end{array}$} & \multicolumn{2}{|c|}{ Linear } & \multicolumn{2}{|c|}{ 2nd degree Poly. } & \multicolumn{2}{|c|}{ 3rd degree Poly. } \\
\hline & & $\Delta \rho(\$)$ & \% Diff. & $\Delta \rho(\$)$ & \% Diff. & $\Delta \rho(\$)$ & \% Diff. \\
\hline 3 & 0.21447 & -0.01581 & -109.17 & -0.02268 & -113.14 & -0.02567 & -114.88 \\
\hline 6 & 0.17368 & -0.03163 & -122.63 & -0.04529 & -132.41 & -0.05121 & -136.64 \\
\hline 12 & 0.11053 & -0.06325 & -171.09 & -0.09032 & -201.52 & -0.10190 & -214.53 \\
\hline 24 & 0.00000 & -0.12650 & \#DIV/0! & -0.17965 & \#DIV/0! & -0.20173 & \#DIV/0! \\
\hline 48 & -0.24868 & -0.25301 & 26.08 & -0.35529 & 77.05 & -0.39532 & 96.99 \\
\hline 96 & -0.69079 & -0.50602 & -9.50 & -0.69456 & 24.22 & -0.75928 & 35.80 \\
\hline 192 & -1.48553 & -1.01203 & -16.29 & -1.32503 & 9.60 & -1.40250 & 16.01 \\
\hline 384 & -2.70789 & -2.02407 & -8.93 & -2.39372 & 7.70 & -2.41572 & 8.69 \\
\hline 492 & -3.24605 & -2.59334 & -3.02 & -2.88221 & 7.78 & -2.87088 & 7.35 \\
\hline 611 & -3.77237 & -3.22059 & 3.25 & -3.32652 & 6.65 & -3.31666 & 6.33 \\
\hline 730 & -4.27105 & -3.84784 & 8.57 & -3.67237 & 3.62 & -3.73862 & 5.49 \\
\hline
\end{tabular}


This page blank. 


\section{INTERNAL DISTRIBUTION}

1. K. J. Beierschmitt (beierschmitt@ornl.gov)

2. S. M. Bowman (bowmansm@ornl.gov)

3. S. E. Burnette (burnettese@ornl.gov)

4. R. A. Crone (cronera@ornl.gov)

5. M. D. DeHart (dehartmd@ornl.gov)

6. R. J. Ellis (ellisrj@ornl.gov)

7. J. C. Gehin (gehinjc@ornl.gov)

8. G. Ilas, (ilasg@ornl.gov)

9. C. V. Parks (parkscv@ornl.gov)

10. R. T. Primm III (primmrtiii@ornl.gov)

11. L. D. Proctor (proctorld@ornl.gov)

12. R. J. Reagan (reaganrj@ornl.gov)

13. K. A. Smith (smithka@ornl.gov)

14. J. C. Wagner (wagnerjc@ornl.gov)

15. RRD Document Control

16. ORNL Laboratory Records (hamrindr@ornl.gov)

\section{EXTERNAL DISTRIBUTION}

17. R. D. Cheverton, 2703 West Gallaher Ferry Road, Knoxville, TN 37932.

18. Dr. G. I. Maldonado, Associate Professor, University of Tennessee, Department of Nuclear Engineering, 311 Pasqua Engineering Building, Knoxville, TN 37996-2300 (maldona@utk.edu).

19. H. L. Dodds, University of Tennessee, Department of Nuclear Engineering, 311 Pasqua Engineering Building, Knoxville, TN 37996-2300 (doddshl@utk.edu)

20. R. D. Rothrock, 705 Cordova Lane, Lenoir City, TN 37771. 